Open Access

\title{
Performance of extended end-plate bolted connections subjected to static and blast- like loads
}

\author{
Ahmed A. Osman * (D) and Sherif A. Mourad
}

\author{
* Correspondence: \\ Ahmedaziz12617@gmail.com; \\ ahmed.abdelaziz@hassanallam.com \\ Faculty of Engineering, Cairo \\ University, Cairo, Egypt
}

\begin{abstract}
In this study, numerical models were developed to predict the behavior of steel extended end-plate moment connections subjected to static and blast-like loading. Two types of extended end-plate connections were considered, stiffened, and unstiffened, with pretensioned bolts. The models were verified by comparing the results with published experimental data. The models were used to compute the moment-rotation curves for the connection under static loading, and then under different blast durations. The pressure impulse diagram and the energy dissipation for the connection under dynamic loading were determined. The failure modes were examined, and the numerical results were compared with the simplified models presented in codes and standards. Improvement in the performance of the connection by adding one or two stiffeners was demonstrated. For the configuration studied, introducing a stiffener increased plastic dissipation energy for blast loading by $45 \%$ compared to the unstiffened connection, whereas under static loading, the plastic energy dissipation for stiffened connection, SC2, was higher than the unstiffened connection by 30\%. A conservative estimate for the dynamic increase factor (DIF) was found to be 1.2 for steel yield stress and 1.05 for bolt failure.
\end{abstract}

Keywords: Extended end-plate connection, Finite element analysis, Pretensioned bolts, Blast load, Pressure-impulse diagram

\section{Introduction}

Many researches have investigated the behavior of end-plate connections under static, cyclic, or seismic loading. Examination of the dynamic behavior of steel connections was motivated by the interest in the seismic performance of steel frames (Popov et al. [1]). Many provisions are currently included in design codes based on experience from damage during earlier earthquakes [2]. However, investigation of the behavior of steel moment-resisting connections under blast loading still needs further attention.

Krauthammer [3] conducted a series of numerical studies on structural concrete and structural steel connection subjected to blast loads, in order to understand the effect of structural details on their behavior. Sabuwala et al. [4] presented the behavior of

(c) The Author(s) . 2021 Open Access This article is licensed under a Creative Commons Attribution 4.0 International License, which permits use, sharing, adaptation, distribution and reproduction in any medium or format, as long as you give appropriate credit to the original author(s) and the source, provide a link to the Creative Commons licence, and indicate if changes were made. The images or other third party material in this article are included in the article's Creative Commons licence, unless indicated otherwise in a credit line to the material. If material is not included in the article's Creative Commons licence and your intended use is not permitted by statutory regulation or exceeds the permitted use, you will need to obtain permission directly from the copyright holder. To view a copy of this licence, visit http://creativecommons.org/licenses/by/4.0/. The Creative Commons Public Domain Dedication waiver (http://creativecommons.org/publicdomain/zero/1.0/) applies to the data made available in this article, unless otherwise stated in a credit line to the data. 
welded steel moment connections under blast loads using the finite element software ABAQUS [5]. The research investigated the behavior of these connections analytically under blast loading and suggested modifications to TM5-1300 [6].

Yim et al. [7] provided a study showing the load-impulse characterization for steel connection under blast loading. Lee et al. [8] presented an analytical approach to understand the nature of blast wave and understand the complex interaction between blast loading and steel column behavior. Hadianfard et al. [9] studied the effect of the shape of column sections and boundary conditions on the behavior and failure of steel columns under blast load are studied. The study identified the importance of elasticplastic properties of sections and proposed criteria for choosing the best section and boundary conditions for columns to resist blast loading.

Grimsmo et al. [10] conducted an experiment to investigate the end-plate moment connection behavior under dynamic load where a trolley hits the connection. The research provided a global overview for the end-plate connections under dynamic loading through studying contact forces between the impact plate and the trolley, the velocity of the impacted column after applying the initial velocity, and the displacement of the connection under the impact test.

Yang et al. [11] provided numerical simulations of rigid steel beam-column joints under impact loads. On the simulated connections, the beam flanges are directly welded to the column and the shear force is transmitted through the fin plate from the beam web to the column flanges. The study provided practical recommendations for the design of welded steel joints under impact loading in accordance with the parameters studied.

Most of the previously mentioned researches focused on one type of moment connections (beam flanges directly welded to the columns and fin plate used to support the beam web). The available research on other moment connection types is limited to static and seismic loading, which confirms that the blast loading problem of steel endplate moment connections is yet to be thoroughly investigated.

\section{Methods}

This research investigates numerically the performance of steel extended end-plate moment connections subjected to static and blast-like loading. Some of the connections represented in the literature $[10,12]$ are modeled using finite element software ABAQUS [5] to verify the results of numerical models against those of the experimental tests. These models are then used to apply blast loading to investigate the behavior of extended endplate moment connections under blast loading. The models are used to compute the moment-rotation curves for the connection under different blast durations. The pressure impulse diagram and the energy dissipation for both static and dynamic loading are determined. The failure modes are examined, and the numerical results are also compared with the simplified models presented in AISC design guide No. 26 [13] and UFC340-02 [14].

\section{Models and verification}

\section{Numerical model and static load validation}

The connections studied by Shi et al. [12] were chosen to validate the finite element model under static loading as detailed below. 


\section{Model geometry}

The dimensions of columns and beams of the connections in the finite element model were identical to those used by Shi et al. [12] and shown in Table 1. The typical connection prototype model is shown in Fig. 1, and details of two of the connections are shown in Table 2. A gradual load was applied to the tip of the beam up to failure to plot the moment rotation curve and other properties of the connections.

\section{Selected elements}

Connections SC2 and SC3-two connections from the eight connections studied by Shi et al. [12] - were modeled for validation of the finite element model under static loading. The finite element program ABAQUS [5] was used for the modeling.

The nut and bolt head were considered as a single body together with the bolt-shank. The threaded part of the bolt shank and extended length of the bolt beyond each nut were ignored. The hexagonal shape of the bolt head and nut was replaced with a cylinder. The typical bolted joint is presented in Fig. 1. All plates, beams, and columns were modeled using 8-node first-order linear hexagon (Brick) elements with reduced integration (C3D8R). For bolts, the 4-node linear tetrahedron elements (C3D4) were used for bolts. Mesh sensitivity analysis was performed to get optimum mesh sizes for bolts, plates, and beams to achieve accurate results and efficient running time. Threaded bolt diameter was considered as $18.65 \mathrm{~mm}$ (i.e., threaded area equal 0.75 nominal bolt area). The details of finite element meshing are shown in Figs. 2 and 3. Finite sliding surfaceto-surface method was considered for all contacts. The surface contact properties between the plate elements were modeled as triangular using the penalty friction option with a friction coefficient value of 0.44 [12]. The hard contact was used for the connection between bolt-head/nut and plate elements to prevent penetration between steel surfaces. Since the bolts are more rigid than hot rolled sections, they were considered as master in contact pairs formulations.

Two models were created; one to input the bolt pretension and the second for applying displacement loading up to failure of connections. The whole procedure may be summarized in the following three steps:

- Step 1. Bolt preloading/activating the contact elements.

- Step 2: Fixing the bolt length.

- Step 3: Applying the external load.

The first model performed the first two steps related to the bolt pretension. Then the results of the first model were imported into a second model through the predefined field option built in ABAQUS Software [5]. During the analysis of the first model for step 1, fictitious supports were added to the mid-surface of the bolt, and the bolt pretension force was applied to it. To allow the program to run and sense the contacts, at

Table 1 Cross-section dimensions of beams and columns Shi et al. [12]

\begin{tabular}{lllll}
\hline & Overall depth $(\mathbf{m m})$ & Web thickness $(\mathbf{m m})$ & Flange width $(\mathbf{m m})$ & Flange thickness $(\mathbf{m m})$ \\
\hline Beam & 300 & 8 & 200 & 12 \\
Column & 300 & 8 & 250 & 12 \\
\hline
\end{tabular}




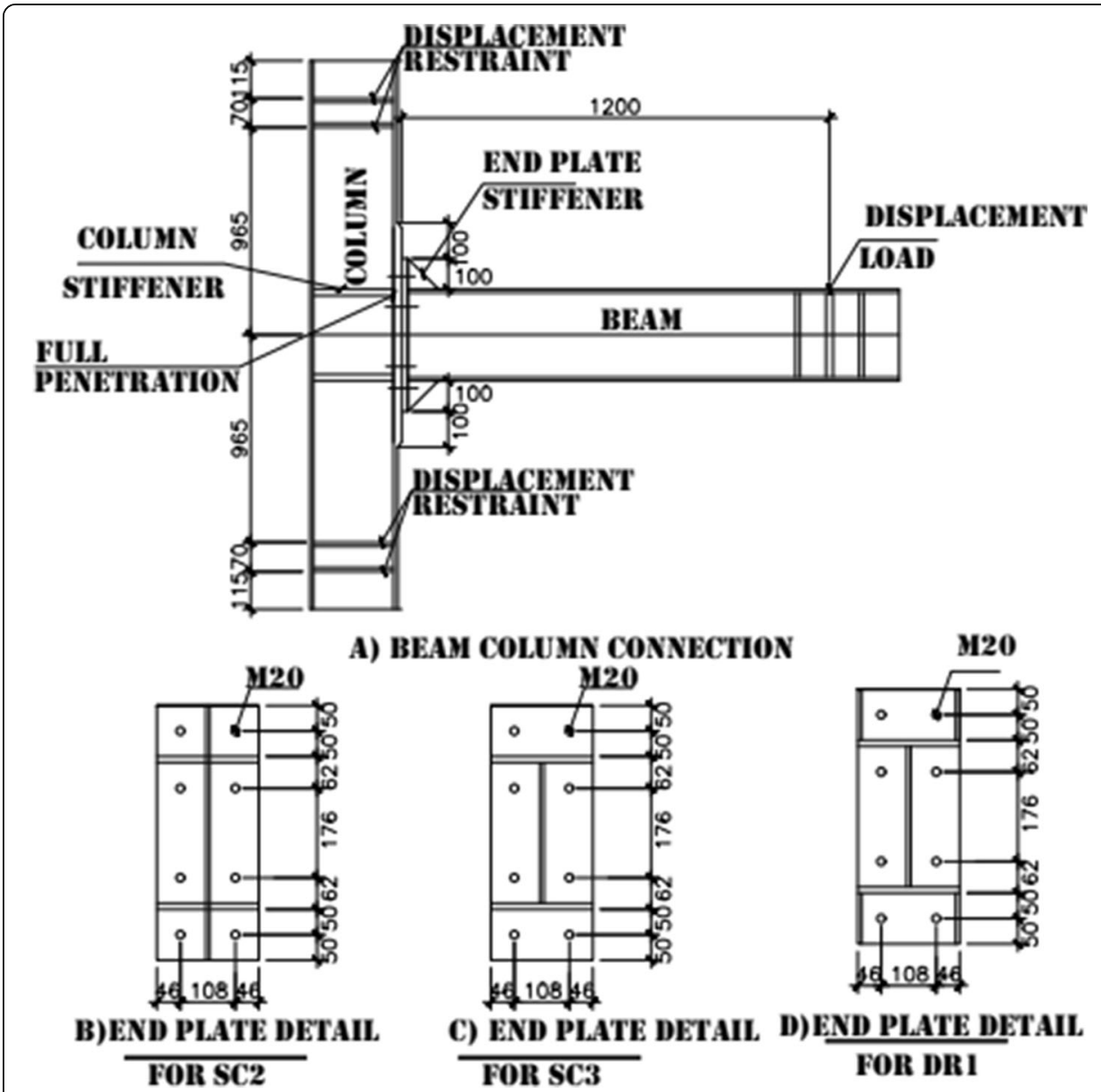

Fig. 1 Connection prototype model including SC2 and SC3 tested by Shi et al. [12] and new proposed connection DR1, proposed by the authors

the beginning of step 2, these supports were deactivated. This approach helped to eliminate the singularity errors, and the program continues the run with results to be corrected at the second step (i.e., fixing the bolt length). The extended end-plate connection consists of a steel $\mathrm{H}$-shaped beam and column (dimensions shown in Table 1), high strength pretension bolts (grade 10.9), end-plate (thickness $20 \mathrm{~mm}$ ), and column stiffener $(12 \mathrm{~mm})$. The specimens were fabricated using Q345B steel. Bolt diameter and bolt pretension values relevant to each test are shown on Table 2. Gradient loading was applied at the beam tip at a distance of $1200 \mathrm{~mm}$ from the column face. The thickness of the column flange at the interface with the end-plate connection was enlarged $100 \mathrm{~mm}$ above and below the extension of the end-plate to have the same thickness as the end-plate. Yield stress and ultimate strength values of the steel plates

Table 2 Types and details of 2 of the 8 connections studied by Shi et al. [12]

\begin{tabular}{llllllll}
\hline $\begin{array}{l}\text { Case } \\
\text { number }\end{array}$ & $\begin{array}{l}\text { Connection } \\
\text { type }\end{array}$ & $\begin{array}{l}\text { End-plate } \\
\text { thickness }(\mathbf{m m})\end{array}$ & $\begin{array}{l}\text { Bolt } \\
\text { diam. } \\
(\mathbf{m m})\end{array}$ & $\begin{array}{l}\text { No. of } \\
\text { bolts }\end{array}$ & $\begin{array}{l}\text { Bolt pretension } \\
\text { force (KN) }\end{array}$ & $\begin{array}{l}\text { Column } \\
\text { stiffener }\end{array}$ & $\begin{array}{l}\text { End-plate } \\
\text { stiffener }\end{array}$ \\
\hline SC2 & Extended & 20 & 20 & 8 & 185 & Yes & Yes \\
SC3 & Extended & 20 & 20 & 8 & 185 & Yes & No \\
\hline
\end{tabular}

The author proposed a new connection called "DR1." It is the same as SC2 but with two end-plate stiffeners 

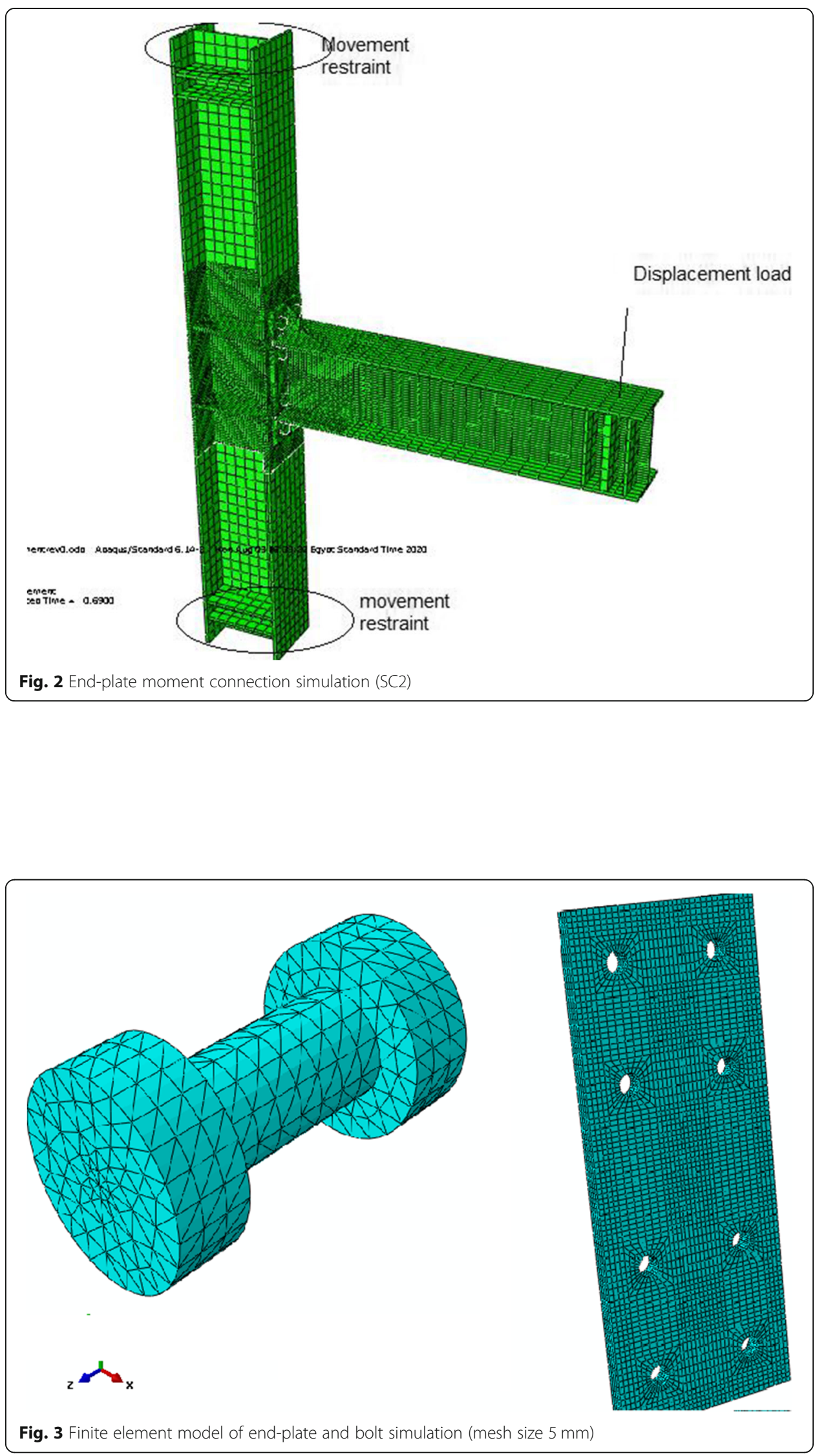
thicker than $16 \mathrm{~mm}$ are 363 and $537 \mathrm{MPa}$, respectively. Young's modulus value was taken as 204,227 MPa and Poisson's ratio 0.3. The stress-strain relationships for plates, beams, and columns as well as the high strength bolts were considered trilinear (Fig. 4).

\section{Fracture modeling}

The failure criteria applied for all models was based on combining both shear and ductile failure of the elements [11].

Fracture models are defined by correlating tri-axial stress to fracture strain. In the models, the parameters given by ABAQUS are normalized by the material fracture strain so that steel with various fracture strains can be modeled. These parameters are then calibrated by existing experimental tests. It should be noted that the effects of strain rate and temperature are not considered. Due to possible ductile or shear failure of steel joints under impact loads, two formulae are derived, as expressed in Eqs. (1) and (2), which establish the relationship of triaxial stress and the normalized fracture plastic strain for ductile and shear failures [11].

$$
\begin{array}{cc}
\mathcal{E}_{\mathrm{fd}} / \mathcal{E}_{\mathrm{u}}=1.13 & \text { for } T^{\sigma} \leq-1 / 3 \\
0.04+0.86 \exp \left(-0.7 T^{\sigma}\right) & \text { for- }-1 / 3<T^{\sigma} \leq 10 / 3 \\
0.12 & \text { for } 10 / 3<T^{\sigma} \\
\varepsilon_{\mathrm{fs}} / \varepsilon_{\mathrm{u}}=0.43 & \text { for } T^{\sigma} \leq 5 / 3 \\
\exp \left(6.69\left(T^{\sigma}-2\right)\right) & \text { for } 5 / 3<T^{\sigma} \leq 2 \\
0.78 & \text { for } 2<T^{\sigma}
\end{array}
$$

where:

$\varepsilon_{u}$ is the ultimate plastic strain of steel;

$\varepsilon_{\mathrm{fd}}$ is the initial fracture plastic strain for ductile failure;

$\varepsilon_{\mathrm{fs}}$ is the initial fracture plastic strain for shear failure;

$T^{\sigma}$ is the stress triaxiality.

Figure 5 shows the relationships of normalized strain and stress triaxiality. In case of ductile failure, the normalized fracture strain is 1.13 when the stress triaxiality is less than $-1 / 3$ and 0.12 when the stress triaxiality is greater than $10 / 3$. A nonlinear

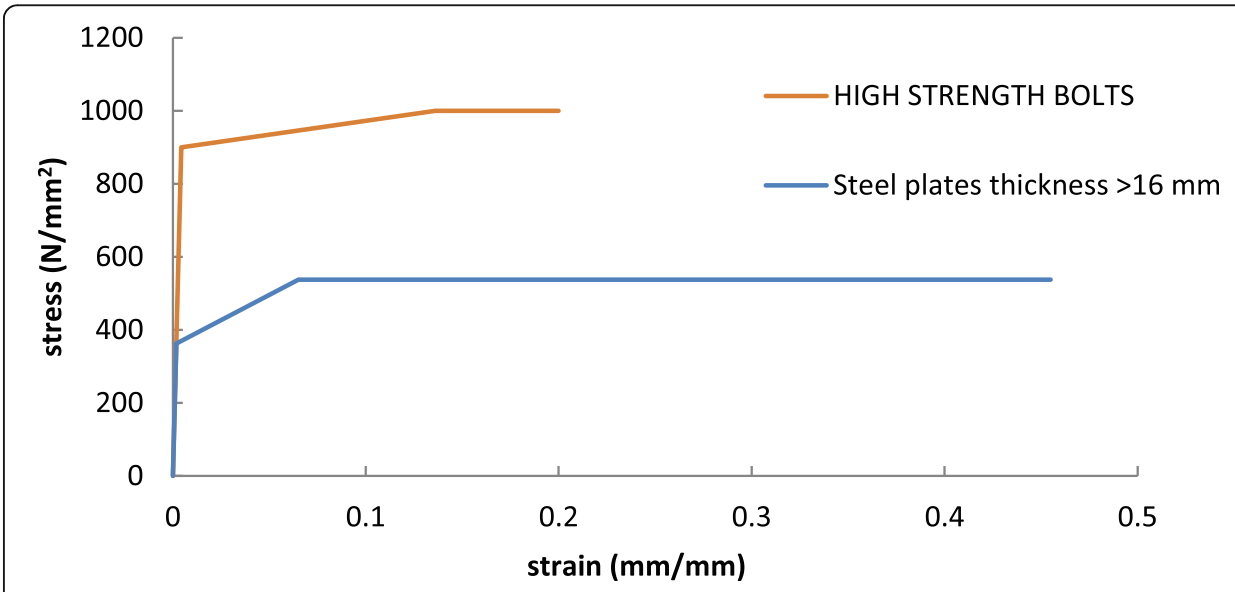

Fig. 4 Trilinear stress-strain curve for steel plates with thickness more than $16 \mathrm{~mm}$ and high strength bolts [13] 


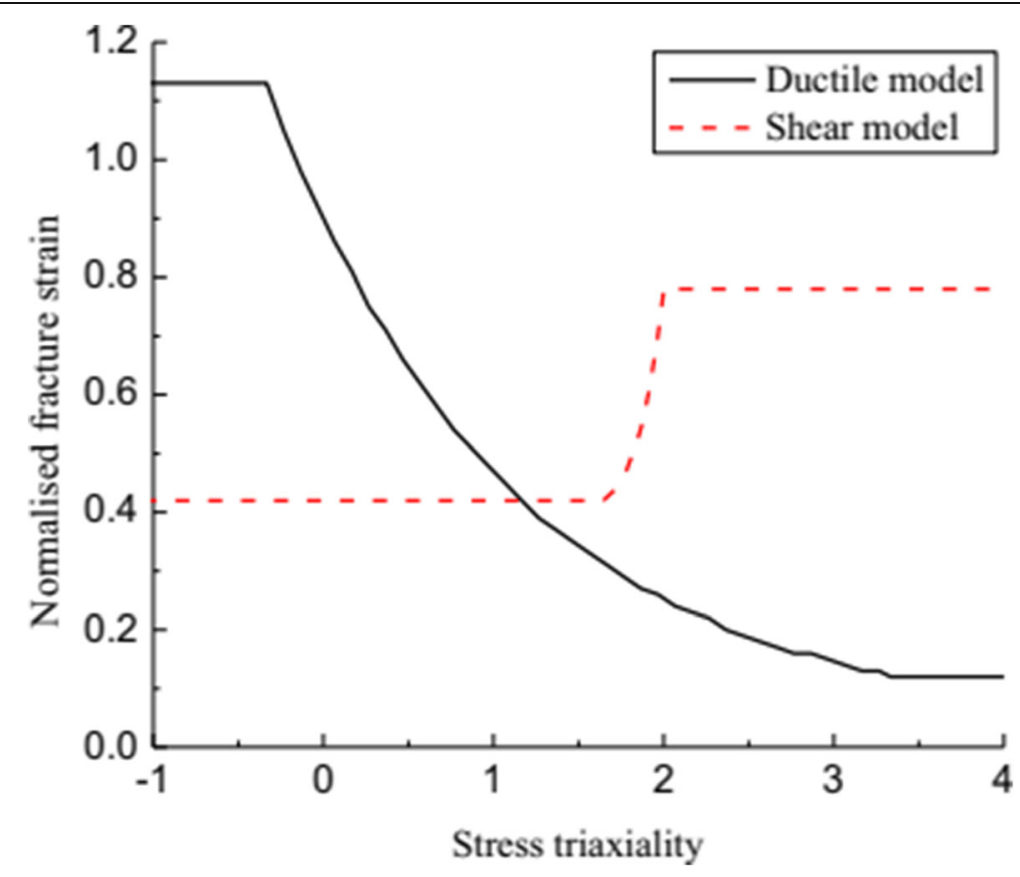

Fig. 5 Fracture model with stress triaxiality for steel material [12]

reduction of the strain can be observed with stress triaxiality between $-1 / 3$ and 10/3 However, the fracture strain increases from 0.43 to 0.78 for shear failure. Therefore, a critical value of 1.17 exists in the fracture strain-stress triaxiality curves. When the stress triaxiality is less than 1.17 , shear failure is dominant over ductile failure; otherwise, ductile failure occurs prior to shear failure. Based on Fig. 5, the fracture models are set in the ABAQUS and employed in the numerical simulations.

The main parameter required to calculate the fracture initiation strain required on ABAQUS input is the ultimate failure strain. The bolt failure strain is taken equal to 0.2 and steel plates are taken equal 0.455 (engineering elastic and plastic strain) [10]. As Grimsmo et al. [10] did not provide the failure strain value directly but provided the fracture initiation strain values for both bolts and plates as 0.07 and 0.16 , respectively, and by substituting in Eq. (1) considering triaxiality for direct tension tests equal - 1/3 [15], one may calculate the value of failure strain. The failure strain of steel plates calculated from Grimsmo et al. [10] was used in Shi et al. [12] FEM modeling as it has a similar high grade of steel and bolts as no fracture analysis data was available. When the element reached the value of fracture strain as defined by Yang et al. [11], the program removes the element and redistributes stresses among the remaining adjacent elements up to complete failure of component. Weld modeling is not considered as no failure in welds was observed. All welds were full penetration and stronger than the steel material itself.

\section{Mesh sensitivity and validation}

In order to choose a suitable size for the finite element mesh, connection SC2 was modeled with 4 sizes of mesh for both bolts and end-plate. The chosen sizes were 10, $7.5,5$, and $2.5 \mathrm{~mm}$. Figure 6 shows the moment-rotation curves of the experimental test 


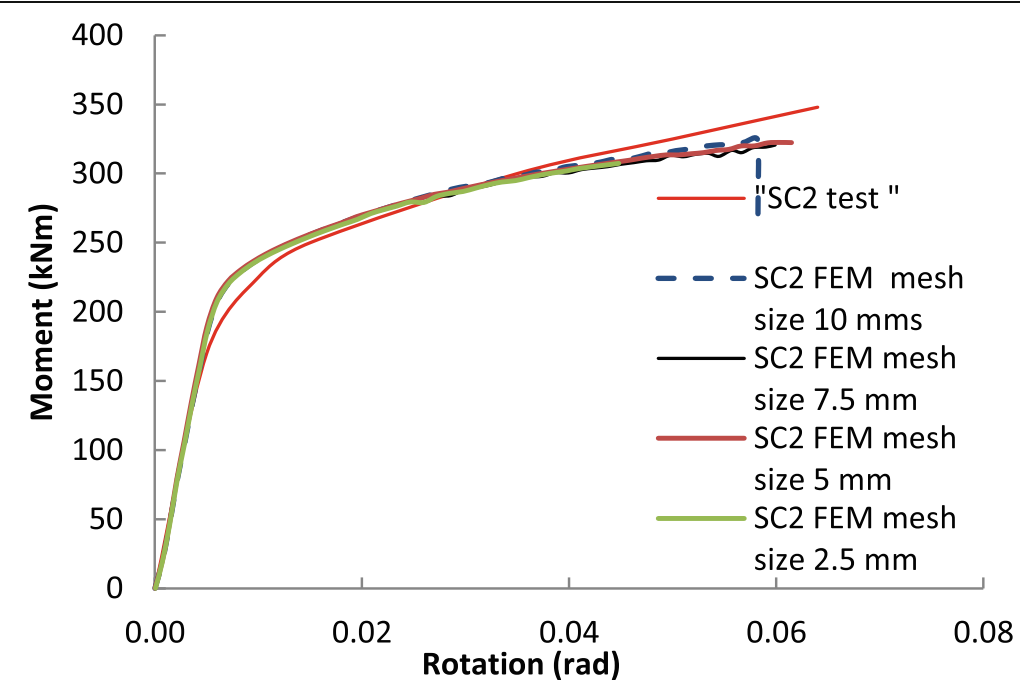

Fig. 6 Mesh sensitivity for M- $\varnothing$ curve for connection SC2

versus the numerical models using the four different mesh sizes. The course meshes of size $10 \mathrm{~mm}$ and $7.5 \mathrm{~mm}$ were unable to predict the ultimate rotation and ultimate moment accurately. Meanwhile, the fine meshes 2.5 and $5 \mathrm{~mm}$ predicted accurately the ultimate rotation and moment. The difference between the 2.5 and $5 \mathrm{~mm}$ was not significant (i.e., the two curves almost coincide); hence, the $5 \mathrm{~mm}$ mesh was used through all numerical models of this paper to achieve the required accuracy within reasonable running time (Fig. 6).

\section{Dynamic problem validation}

An experiment was conducted [10] to investigate the behavior of end-plate moment connection under impact load. The published results of this experiment were used to validate the results versus the FEM result.

\section{Connection geometry}

Figure 7 shows the dimensions of the tested connection. It consisted of a column section of HEB220 fixed to two beams of HEA180 with end-plates of $12 \mathrm{~mm}$ thickness. Meanwhile, the bolts were M16 arranged as shown in Fig. 8.

\section{Material modeling}

The steel material for members and plates has been input to the FEM considering the elastic trilinear relationship with yield stress value of steel equal $413.7 \mathrm{MPa}$ for endplate (Fig. 9). Moreover, trilinear relationship is considered for bolts.

\section{Finite element model}

A trolley was used to hit the impact plate by speed up to $12 \mathrm{~m} / \mathrm{s}$. The weight of the trolley used on the analysis equals the actual weight of $727 \mathrm{~kg}$ and the impact plate was welded firmly to the bottom of the column [16]. The trolley was 


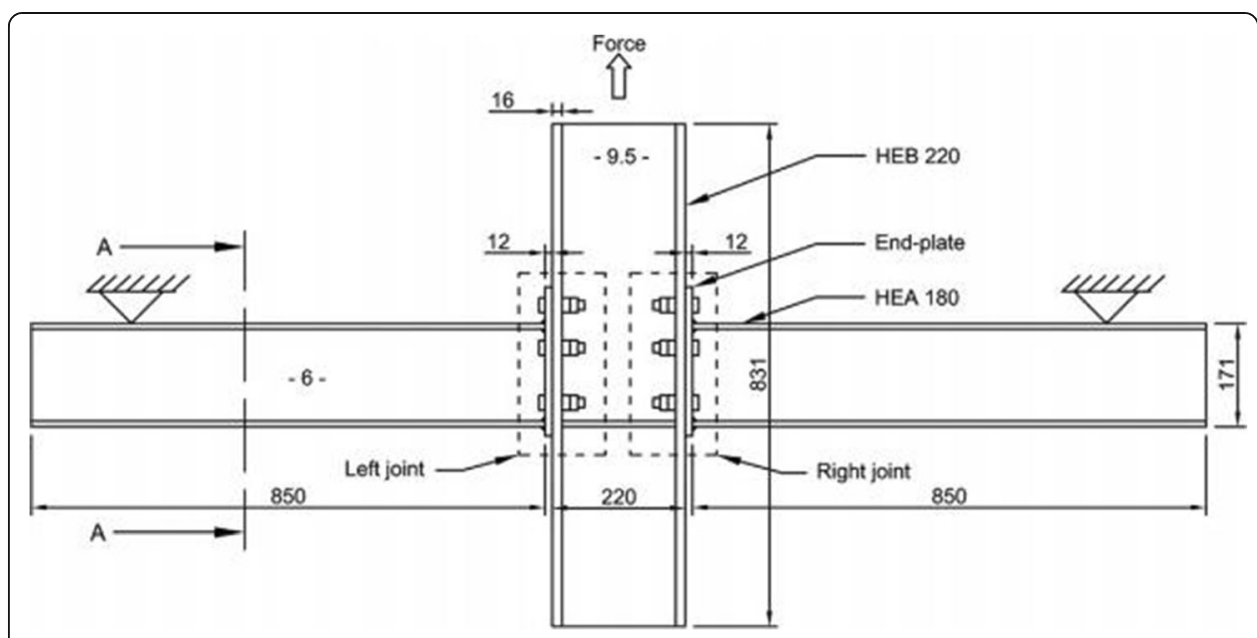

Fig. 7 Elevation view for the connection [10]

modeled as a concentrated mass of $727 \mathrm{~kg}$ and the velocity of $12 \mathrm{~m} / \mathrm{s}$ was applied to this point.

An ABAQUS model was created to validate the results of numerical dynamic analysis versus the published test results conducted [10]. All plates, beams, and columns were modeled using 8-node first-order linear hexagon (Brick) elements with reduced integration (C3D8R) with a fine mesh of $5 \mathrm{~mm}$ for end-plates; meanwhile, the bolts were modeled as tetrahedron elements with a mesh size of $5 \mathrm{~mm}$ and elements (C3D4). The finite element model is shown in Fig. 10 whereas a close-up on the meshing of the bolts and nuts is shown in Fig. 11. Finite sliding surface-to-surface method was considered for all contacts. The surface contact properties between the plate elements were modeled using the penalty friction

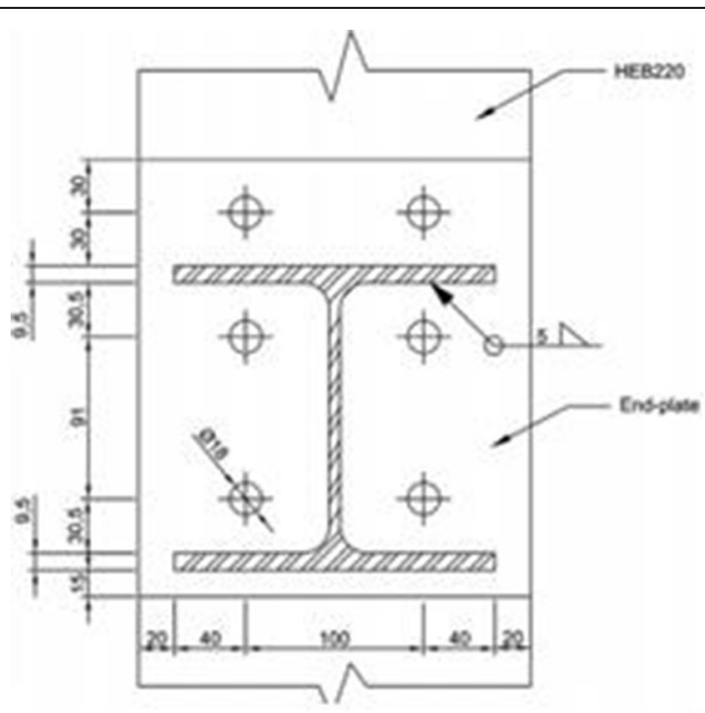

\section{c) section (A-A) view of end plate and cross section of the beam for DLD specimen}

Fig. 8 End-plate dimensions and bolts (M16) arrangement [10] 


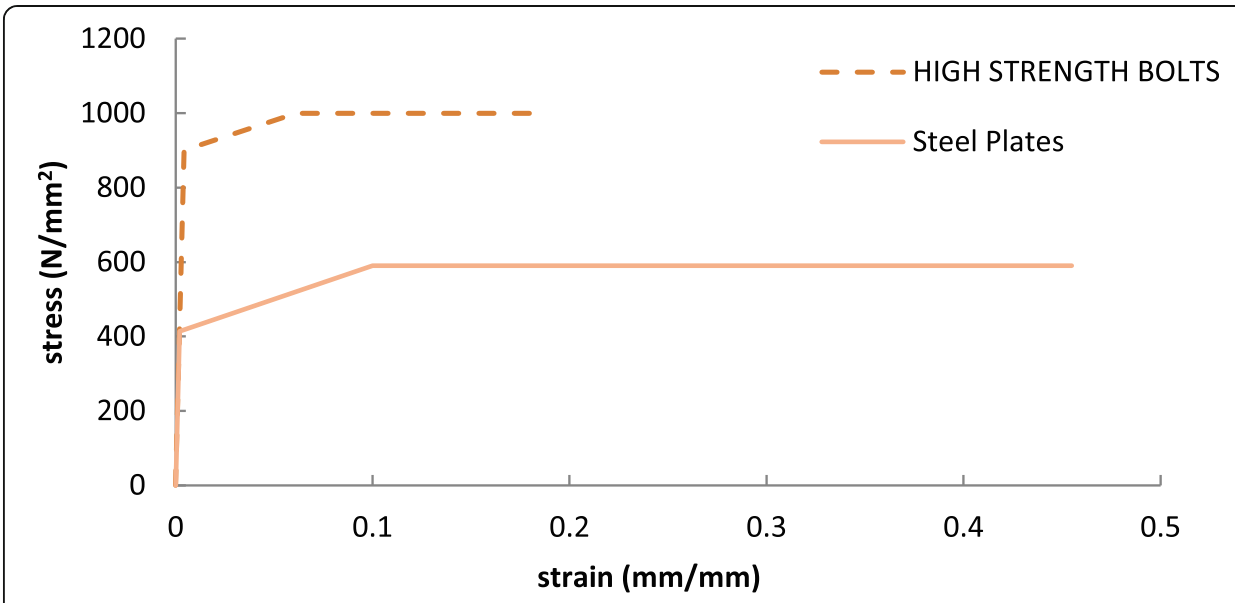

Fig. 9 Trilinear stress-strain curve for steel plates and high strength bolts [16]

option with a friction coefficient value of 0.2 for all contact surfaces [16]. The hard contact was used for the connection between bolt-head/nut and plate elements to prevent penetration between master in contact pair's formulations steel surfaces. The bolts are more rigid than hot rolled sections and thus were considered as master. A dynamic bolt pretension is modeled using the same procedure explained previously. Bolt tightening value equal $80 \mathrm{~N} \mathrm{~m}$ was incorporated to all bolts modeling on this model. For more details on the experiments, refer to [10].

The fracture model explained earlier was considered in this analysis. Calculated values of engineering failure strain of 0.455 and 0.185 were based on published fracture initiation values of 0.16 and 0.07 for both steel plates and bolts, respectively. Triaxiality value for direct tension tests was considered equal to $-1 / 3$ when substituting in Eq. (1). Moreover, no fracture modeling is considered for weld as no expected failure on this weld. The effect of the dynamic load was incorporated on the material model by

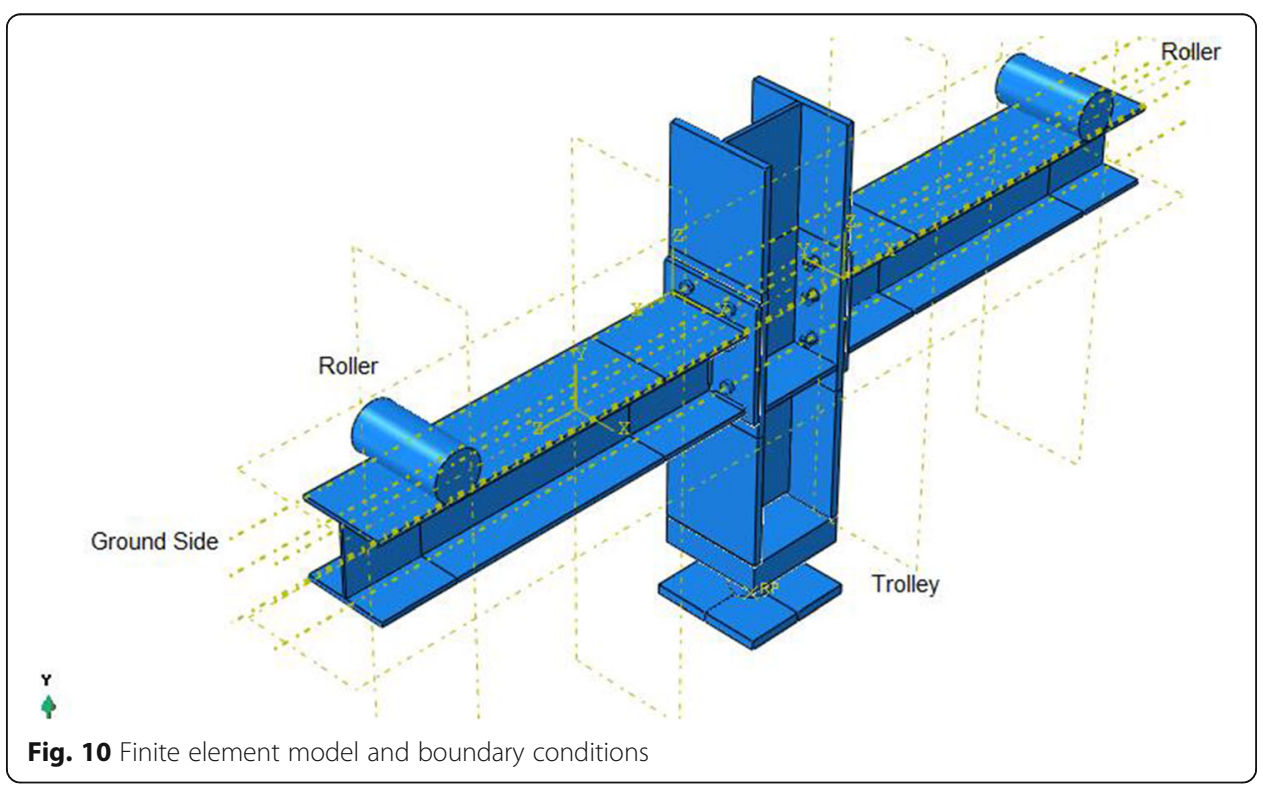



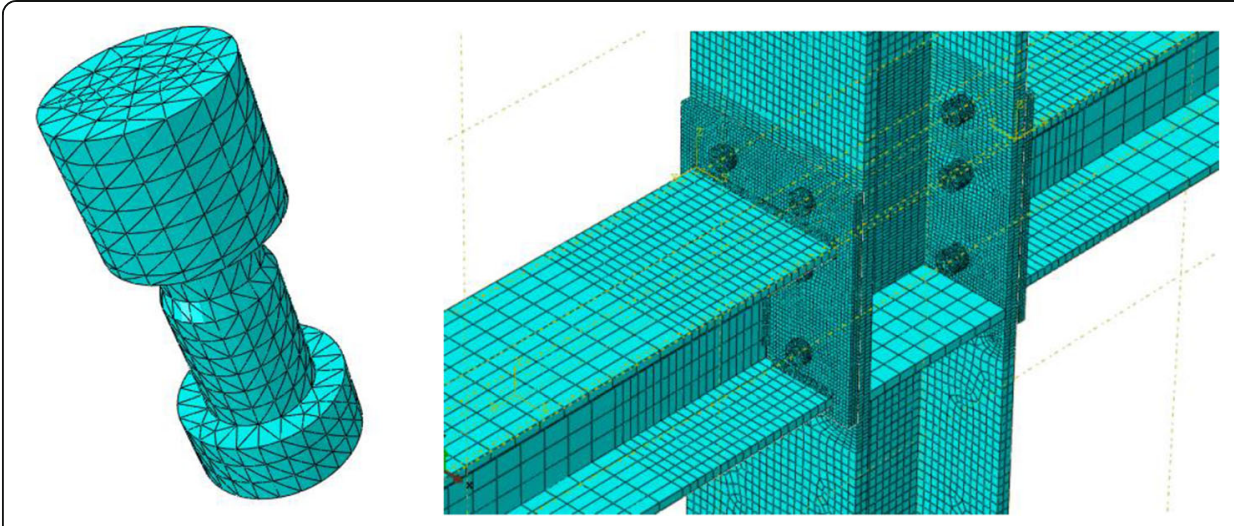

Fig. 11 Bolt and nut meshing/model meshing

applying the strain rate effect using the Cowper Symonds model [2], which is built in the ABAQUS code.

\section{Comparison of results}

Figure 12 presents a comparison of the force time history measured from the test [10] and that from the finite element analysis, whereas Fig. 13 presents the trolley velocity time history comparison. Figures 12 and 13 show close agreement between the validated FEM model and the published test results. The percentage of error in estimating the maximum force between the impact plate and the nose of the trolley was $3 \%$. Moreover, Figs. 14 and 15 show that the model was able to predict the mode of failure and deformation.

\section{Results and discussions}

\section{Model geometry and problem description}

The behavior of extended end-plate connection is investigated under static and blastlike loads. Two connections that were studied earlier by Shi et al. [12] were modeled:

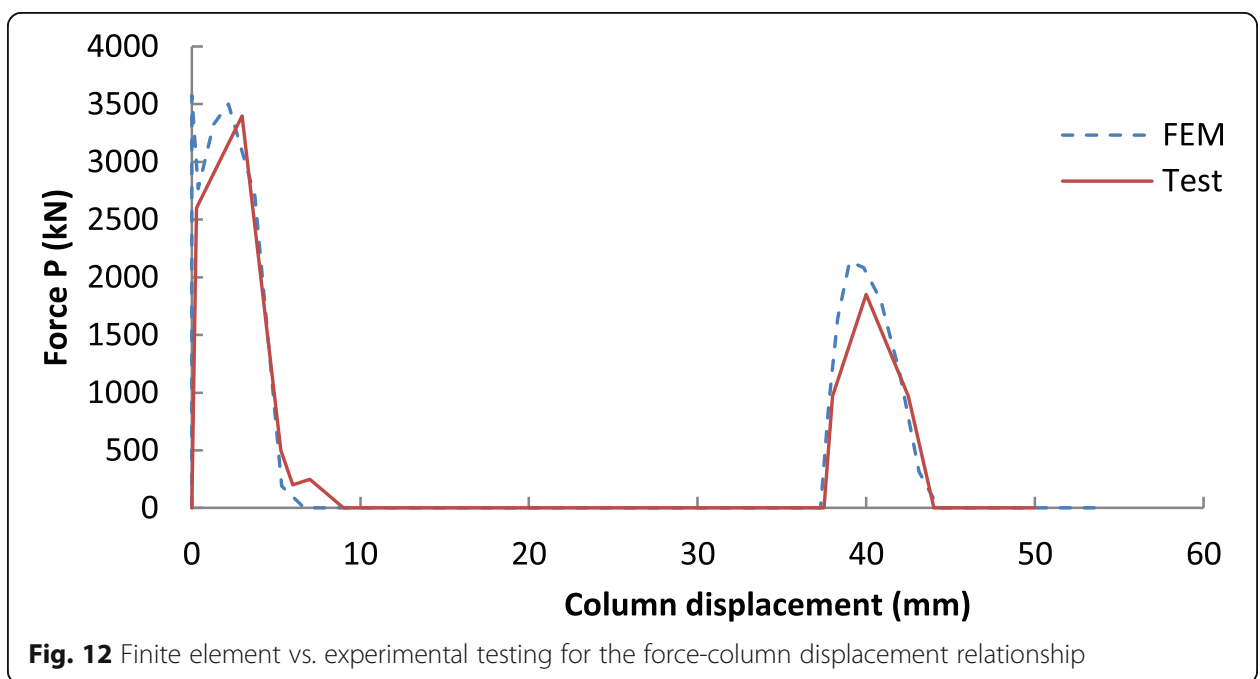




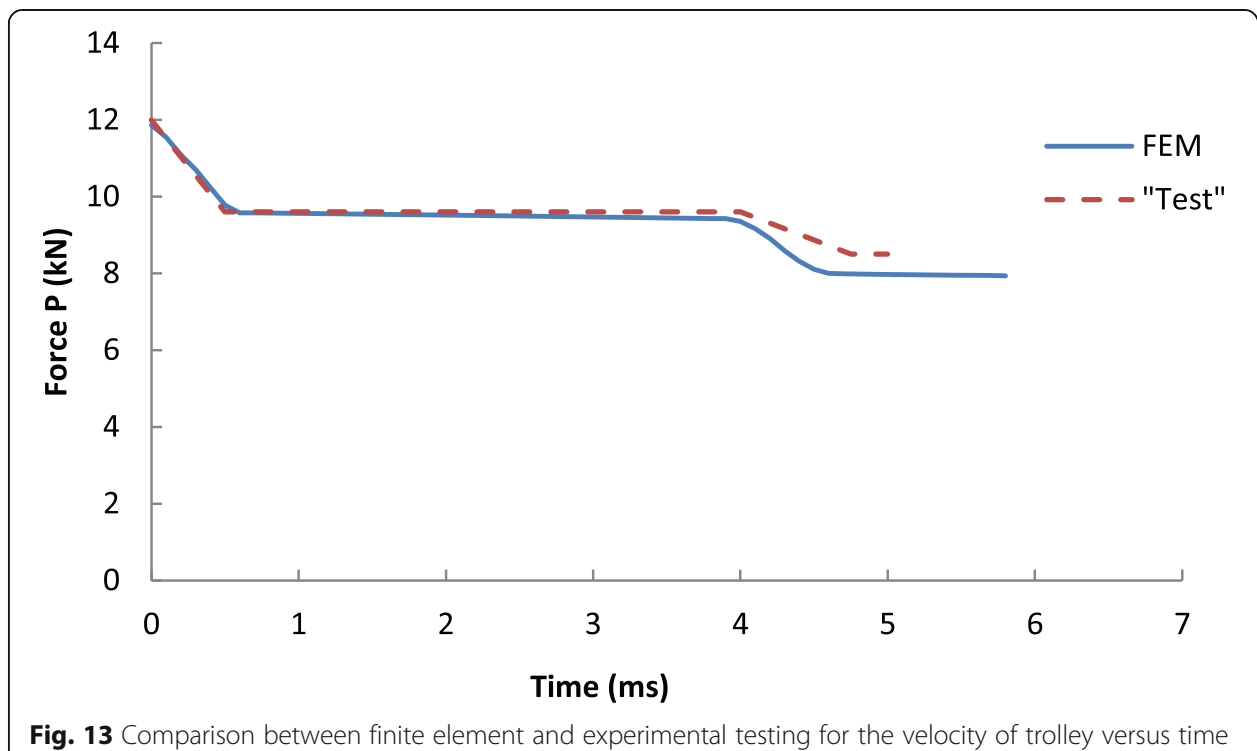

SC2 and SC3. A new proposal of a third connection, DR1, proposed by the author having two (double) rib stiffeners was also examined (Fig. 1d).

For blast loading, the problem of internal fully vented blast loading is studied. Only blast pressure is considered in the analysis. The modeling procedure outlined earlier on static loading tests [12] was used in this stage, except that the applied load was blast loading.

\section{Material and finite element modeling}

In order to be able to apply the pretension on the connection subjected to dynamic loading, the approach presented by Krolo et al. [17] was used and may be summarized in the three steps mentioned in the "Selected elements" section.

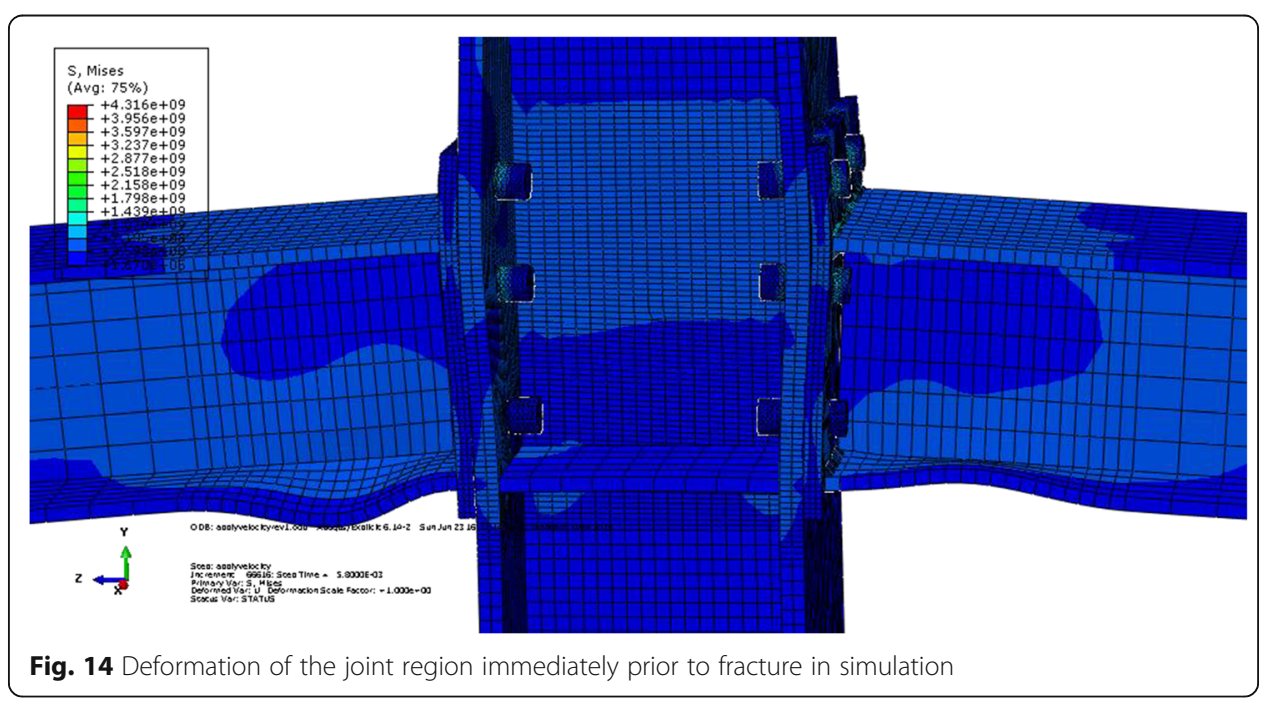




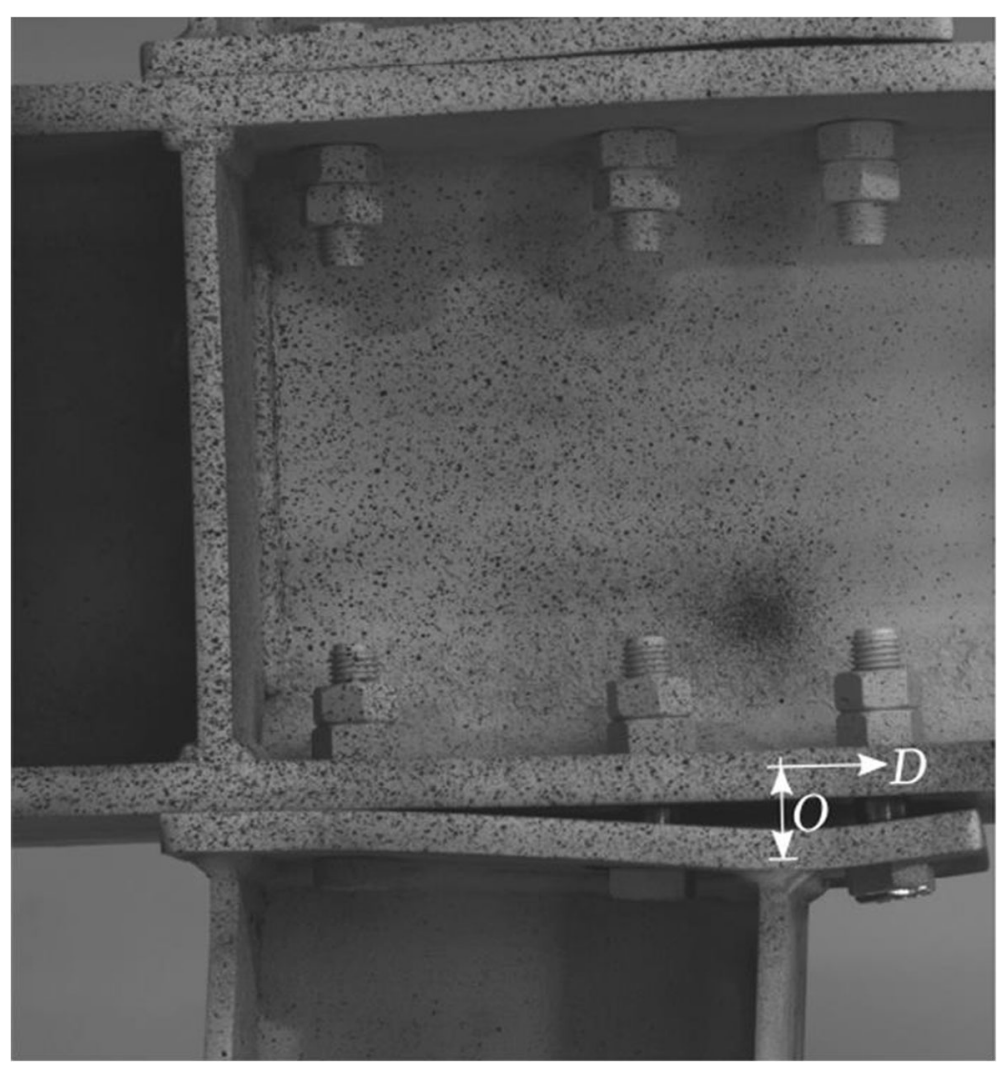

Fig. 15 Deformation of the joint region immediately prior to fracture in the test by [10]

Three models were investigated. These models are SC2, SC3, and DR1. The effect of the dynamic load was incorporated on the material model by applying the strain rate effect using the Cowper Symonds model. The Cowper Symonds model [2] is built in the ABAQUS code. The equation of Cowper Symond is as follows:

$$
\frac{\sigma_{d}}{\sigma_{o}}=1+\left(\frac{\varepsilon_{o}}{D}\right)^{1 / q}
$$

where $\sigma_{\mathrm{d}}$ is the dynamic yield strength calculated as a function of instantaneous strain rate, $\sigma_{0}$ is the nominal static yield strength, $\varepsilon_{0}$ is the instantaneous strain rate, $D$ and $q$ are materials constants and were selected as $D=40.4$ and $q=5$ for steel materials [2]. The dynamic increase factor was calculated automatically by the program for each dynamic analysis case.

The same connection details used in the validation stage were used in this stage (i.e., blast loading) except that the beams and columns length were updated to be $3 \mathrm{~m}$ long. The dynamic pressure was applied on the inner face of both the beam and the column. A fine mesh of $5 \mathrm{~mm}$ was used for both end-plate and bolts to assure accuracy based on mesh sensitivity analysis. The same fracture modeling of the "Fracture modeling" section was also used, and the same material stress-strain curves are shown in Figs. 4 and 5. The blast pressure was applied to the interior flanges of both the beam and the column at a certain load duration until failure of the connection. Thus, one can get the pressure value corresponding to the blast duration that caused the failure of the 
connection. Then one can multiply half the pressure value by the corresponding time to get the impulse, in order to plot the pressure impulse diagram for each connection. The impulse diagrams provide the maximum pressure value corresponding to the maximum impulse which is defined as the area under the curve of the applied dynamic pressure at a specific explosion period. The points under the curve are considered safe values; meanwhile, the points above the curve are considered unsafe. Full details on the modeling may be found in Ref. [18].

\section{Static load results}

The steel design guide No. 16 [19] proposes equations that may be used to obtain numerical values for connection nominal resistance as follows (Fig. 16):

\section{End-plate yield equations}

$$
\begin{aligned}
& \mathrm{M}_{\mathrm{n}}=\mathrm{M}_{\mathrm{p}}=\mathrm{F}_{\mathrm{py}} \mathrm{t}_{\mathrm{p}}{ }^{2} \mathrm{Y} \\
& \boldsymbol{Y}=\frac{\boldsymbol{b}_{\boldsymbol{p}}}{\mathbf{2}}\left(\boldsymbol{h}_{\mathbf{1}}\left(\frac{\mathbf{1}}{\boldsymbol{p}_{\boldsymbol{f}, \boldsymbol{i}}}+\frac{\mathbf{1}}{\boldsymbol{S}}\right)+\boldsymbol{h}_{\mathbf{0}}\left(\frac{\mathbf{1}}{\boldsymbol{p}_{\boldsymbol{f}, \mathbf{0}}}\right)-\frac{\mathbf{1}}{\mathbf{2}}\right)+\frac{\mathbf{2}}{\boldsymbol{g}}\left(\boldsymbol{h}_{\mathbf{1}}\left(\boldsymbol{p}_{\boldsymbol{f}, \boldsymbol{i}}+\boldsymbol{s}\right)\right) \\
& \boldsymbol{S}=\frac{\mathbf{1}}{\mathbf{2}} \sqrt{ }\left(\boldsymbol{b}_{\boldsymbol{p}} \boldsymbol{g}\right)
\end{aligned}
$$

where:

$M_{n}$ : Nominal moment resistance of connection

$\boldsymbol{M}_{\boldsymbol{p}}$ : Nominal moment resistance due to end-plate yielding.

$\boldsymbol{F}_{\boldsymbol{p} \boldsymbol{y}}$ : Yield stress of steel.

The remaining parameters in Eqs. (5) and (6) are geometric parameters defined in Fig. 16.

\section{Bolts rupture model}

$$
M_{n}=M_{n b}=2 P_{t}\left(h_{0}+h_{1}\right)
$$

where:

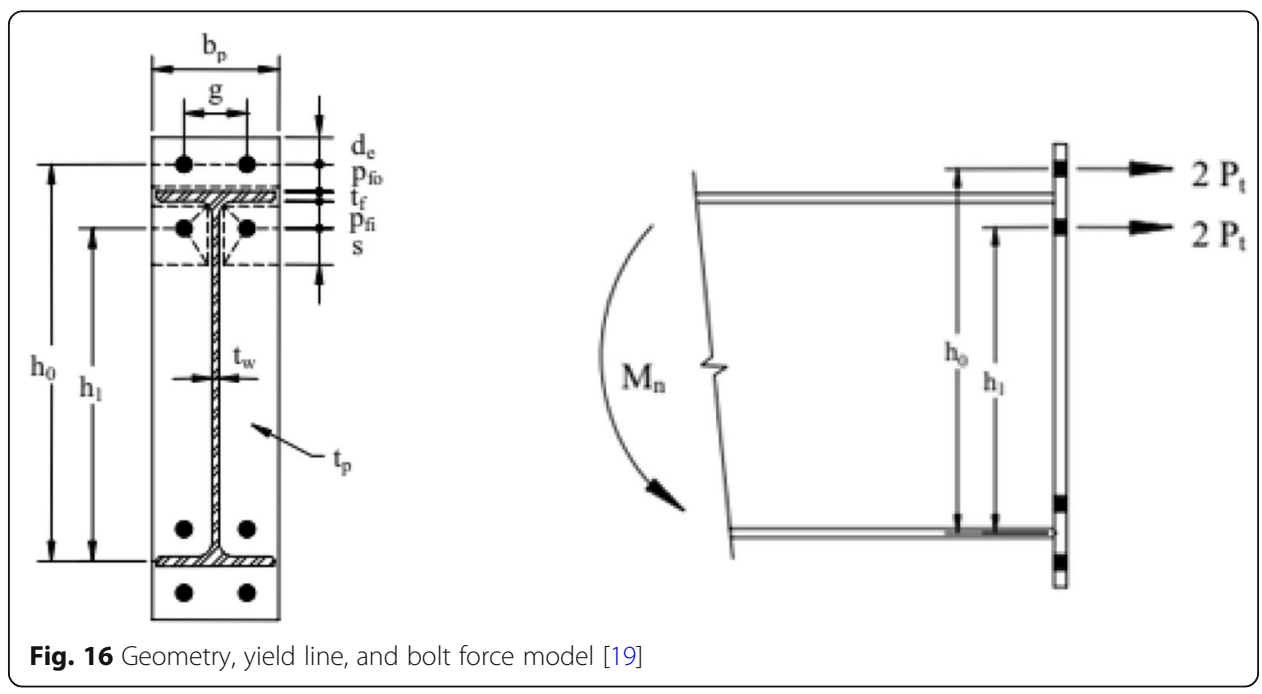


$\boldsymbol{M}_{\boldsymbol{n} \boldsymbol{b}}$ : Nominal moment resistance due to bolt rupture.

$\boldsymbol{P}_{\boldsymbol{t}}$ : Ultimate bolt tensile strength.

$\boldsymbol{h}_{\boldsymbol{b}}$ : Distance from compression flange centerline to the uppermost two bolts

$\boldsymbol{h}_{\boldsymbol{1}}$ : Distance from compression flange centerline to the second row of two bolts.

The failure for connection SC3 was due to end-plate yielding, and $\boldsymbol{M}_{\boldsymbol{n}}$ was computed as $296.5 \mathrm{kN} \mathrm{m}$. Meanwhile, for connections SC2 and DR1, bolt failure was the reason for connection failure. $\boldsymbol{M}_{\boldsymbol{n} \boldsymbol{b}}$ was found to be $348 \mathrm{kN} \mathrm{m}$ for SC2. Although the design guide does not provide a formula for the double rib stiffener connection (DR1), its capacity may be assumed equal to $\mathrm{SC} 2$, since they were both governed by bolt failure.

Figure 17 shows the strain distribution at ultimate load for connection SC3. Values indicated are the equivalent plastic strain of steel computed by ABAQUS. Higher values as shown in Fig. 17 indicate end-plate yielding. Figure 18 shows the strain distribution for SC2. The values of equivalent plastic strain for SC2 are much lower than SC3. A closer look at the bolt strain (Fig. 19) showed excessive strain, which confirms the failure of bolts. Table 3 shows the ultimate load values and ultimate moment values obtained from the analysis model versus test published values. Meanwhile, Fig. 20 shows the mode of connection failure for DR1 under static load and dynamic blast load (i.e., bolt rupture). The calculated moments shown in Table 3 are based on equations given by AISC design guide 16 [19].

\section{Blast-like load results}

Figure 21 shows model geometry and location of blast load application. Typically, blast loading may be modeled using one of three alternatives: Arbitrary Lagrangian Eulerian (ALE), Load Blast Enhanced (LBE), and pressure-time history methods. Earlier research [20] concluded that using pressure-time history can predict the displacement response due to blast loading with sufficient accuracy as compared to the other two techniques, while providing substantial saving in computational time. Thus, in this research, the pressure-time history analysis technique was adopted, also to be consistent with design guide No.26 [13] and UFC 340-02 [14] analysis methods.

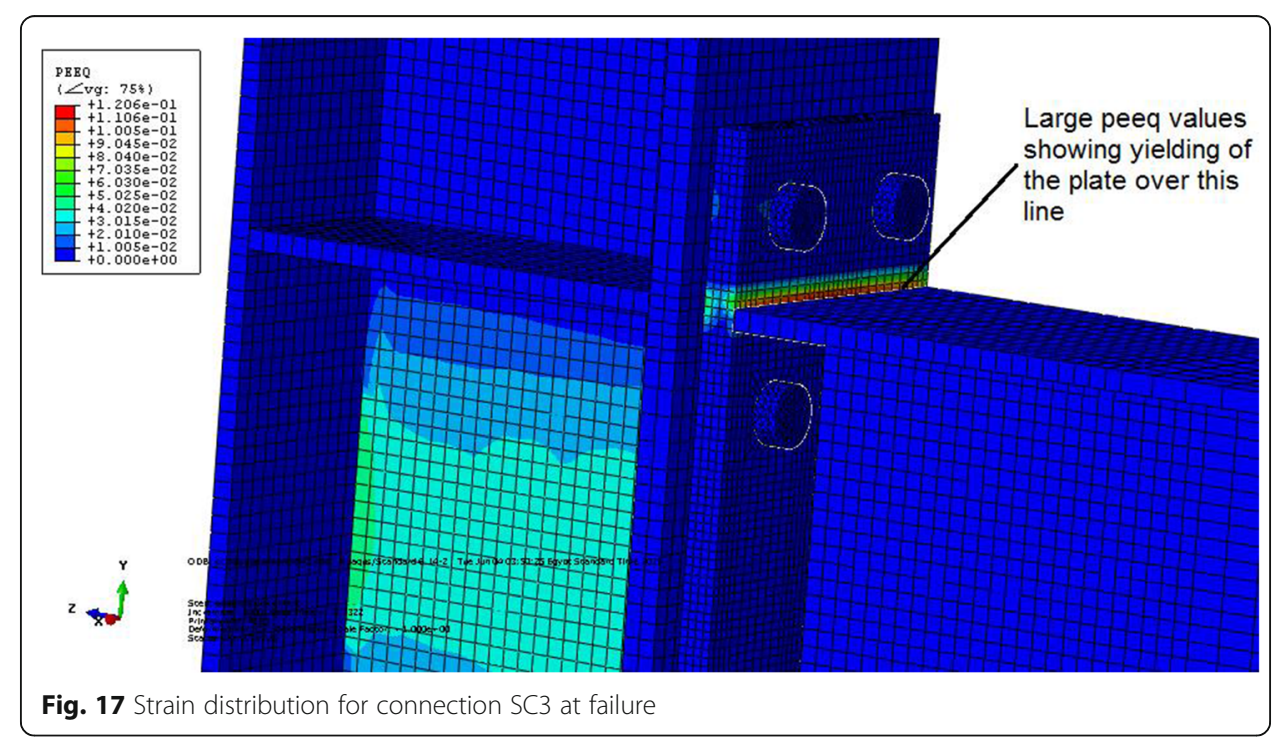




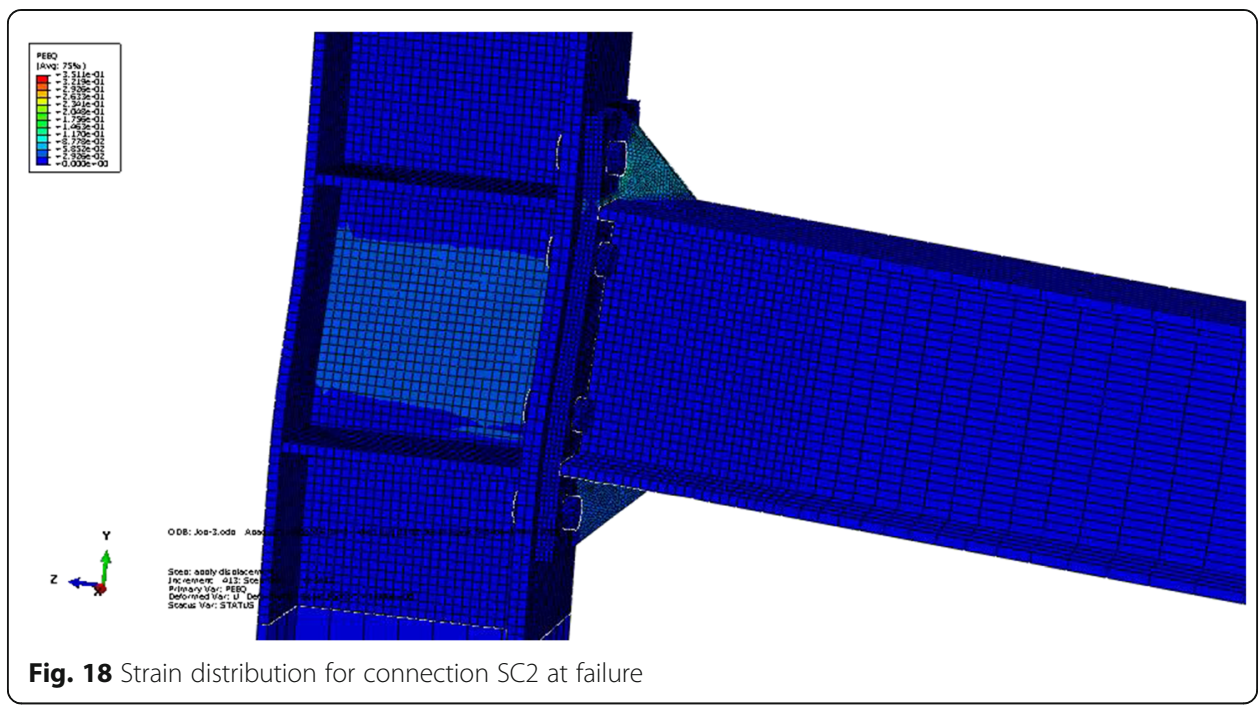

Figure 22 shows different time duration versus corresponding pressure values for connection SC2. The same time durations are used for SC3 and DR1 with different pressure values. The problem examined is an explosion inside a fully vented room of dimensions $6.0 \times 6.0 \times 6.0 \mathrm{~m}$. Only half the frame was considered for analysis due to symmetry. For the case of fully vented room (i.e., one wall missing), the gas pressure may be neglected as per UFC 340-02 [14].

It is observed that failure of connections considering different blast duration was limited to end-plate yielding for unstiffened connection, SC3 (Fig. 23), whereas the lowermost four bolts failed as shown in Fig. 24 for the stiffened connections, SC2 and DR1.

Figures 25, 26, and 27 show the moment rotation time history for all blast time durations used in this research for connections SC2, SC3, and DR1. Various blast loading

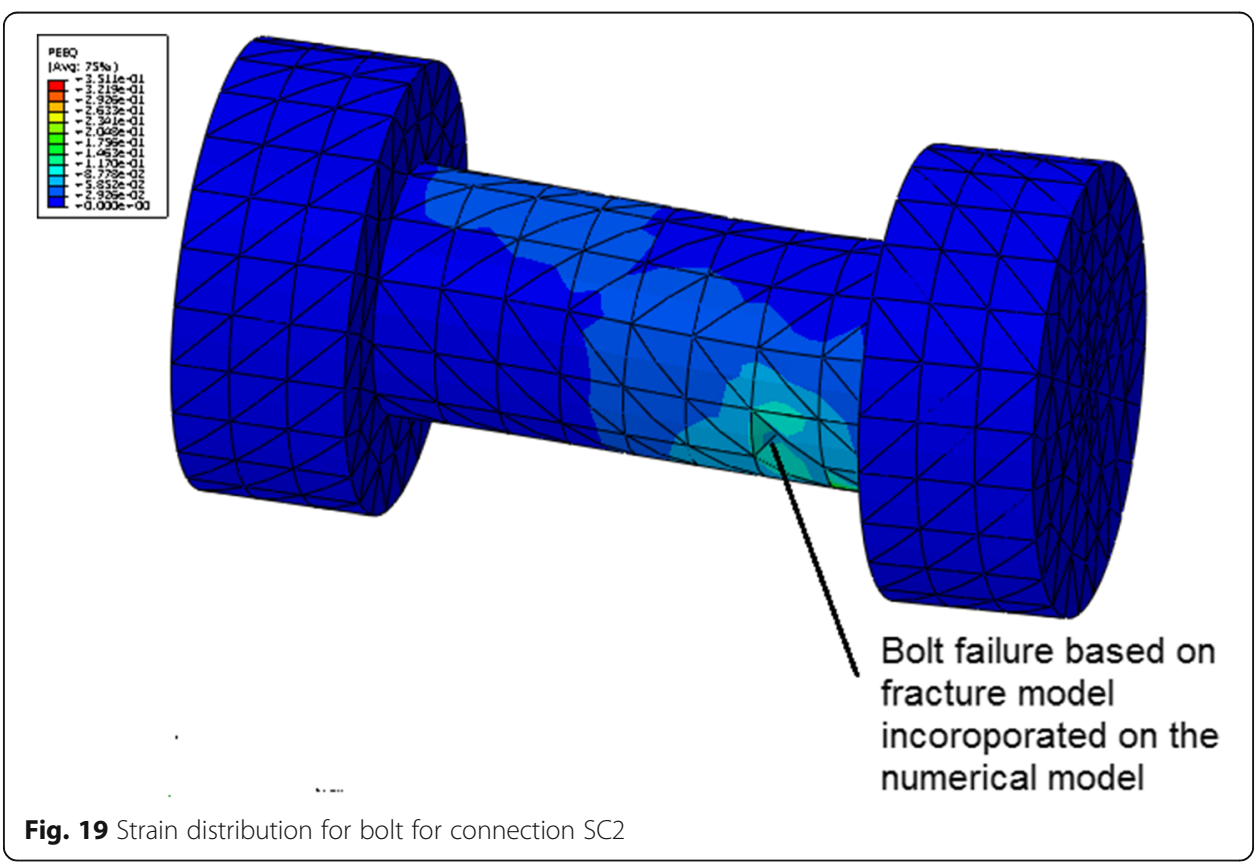


Table 3 Comparison of loading capacities between FEA and tests

\begin{tabular}{|c|c|c|c|c|c|c|c|}
\hline \multirow{2}{*}{$\begin{array}{l}\text { Specimen } \\
\text { number } \\
\text { Note }\end{array}$} & \multicolumn{2}{|c|}{ Test by Shi et al. (2008) } & \multicolumn{2}{|l|}{ FEA } & \multirow{2}{*}{$\begin{array}{l}\text { FEA/ } \\
\text { test }\end{array}$} & \multirow[t]{2}{*}{ Failure mode } & \multirow{2}{*}{$\begin{array}{l}\text { Calculated* } \\
\text { Moment }\end{array}$} \\
\hline & $\begin{array}{l}\text { Loading } \\
\text { capacity } \\
\text { (kN) }\end{array}$ & $\begin{array}{l}\text { Moment } \\
\text { resistance } \\
(\mathrm{kN} \mathrm{m})\end{array}$ & $\begin{array}{l}\text { Loading } \\
\text { Capacity } \\
\text { (kN) }\end{array}$ & $\begin{array}{l}\text { Moment } \\
\text { Resistance } \\
(\mathrm{kN} \mathrm{m})\end{array}$ & & & \\
\hline SC2 & 286.4 & 343.7 & 268 & 322 & 0.94 & $\begin{array}{l}\text { Bolt failure } \\
\text { (Figs. } 18 \text { and } \\
\text { 19) }\end{array}$ & 348 kN m \\
\hline SC3 & 256.9 & 308.3 & 238 & 286 & 0.93 & $\begin{array}{l}\text { End-plate } \\
\text { yielding (Fig. } \\
\text { 17) }\end{array}$ & $296.5 \mathrm{kN} \mathrm{m}$ \\
\hline DR1 & $\begin{array}{l}\text { New } \\
\text { proposal }\end{array}$ & New proposal & 270.8 & 325 & & $\begin{array}{l}\text { Bolt failure } \\
\text { (Fig. 20) }\end{array}$ & N.A. \\
\hline
\end{tabular}

durations are applied to the models of connections SC2/SC3/DR1 (0.005, 0.01, 0.015, and $0.02 \mathrm{~s}$ ). Comparing the figures, it is clear that the connection SC3 (without the additional end-plate rib stiffener) has a higher rotational capacity.

A separate model was created considering each blast duration period, and the peak pressure was increased gradually until the pressure value that causes the connection to fail was obtained. The resulting pressure impulse diagrams for the three connections are shown in Fig. 28. It is clear by comparing SC2 and SC3 that connection SC2 has higher pressure resistance for the same blast duration. The increase in pressure resistance is about 4\%. Meanwhile, comparing SC3 with DR1 indicates that DR1 has higher pressure resistance (about 6\% higher).

UFC 340-02 proposes a dynamic increase factor (DIF) of 1.05 for failure due to ultimate stress (bolt failure) whereas the value increases to a range from 1.2 to 1.3 for failure due to yielding (steel plate failure).

The dynamic yield stress is calculated as follows:

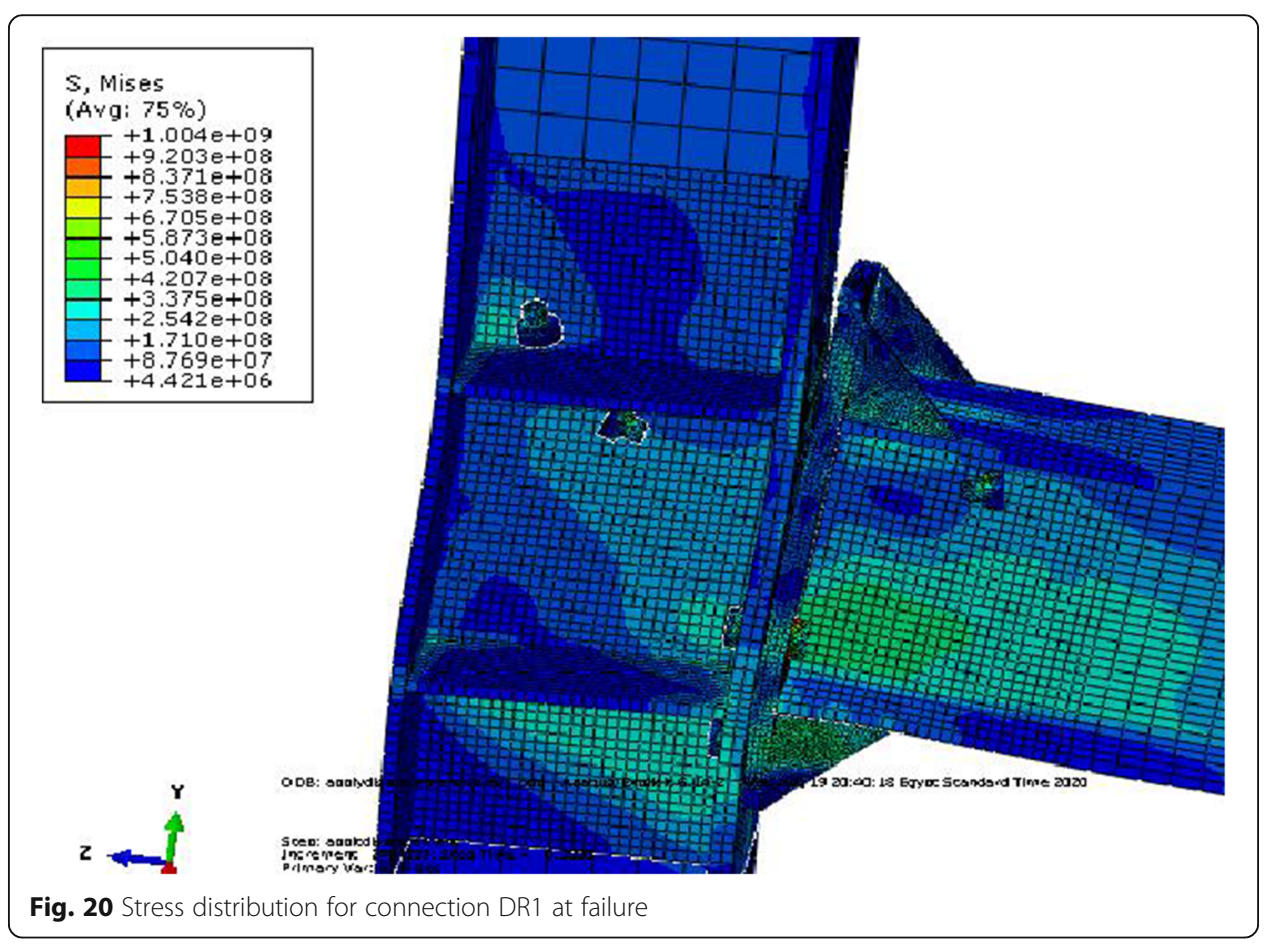




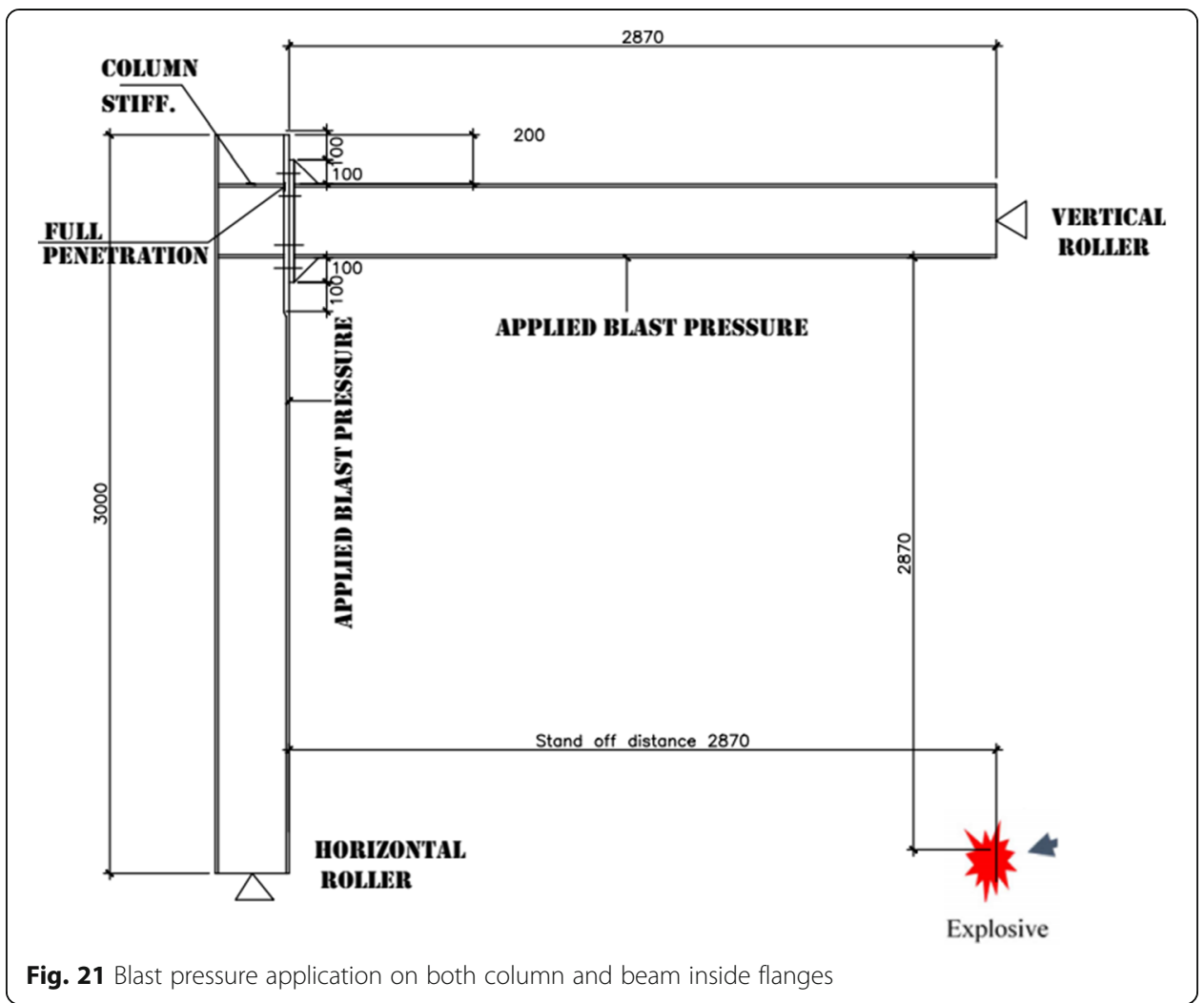

Fds $=$ DIF $\times$ Fys

where:

Fds: dynamic yield stress

Fys: static yield stress

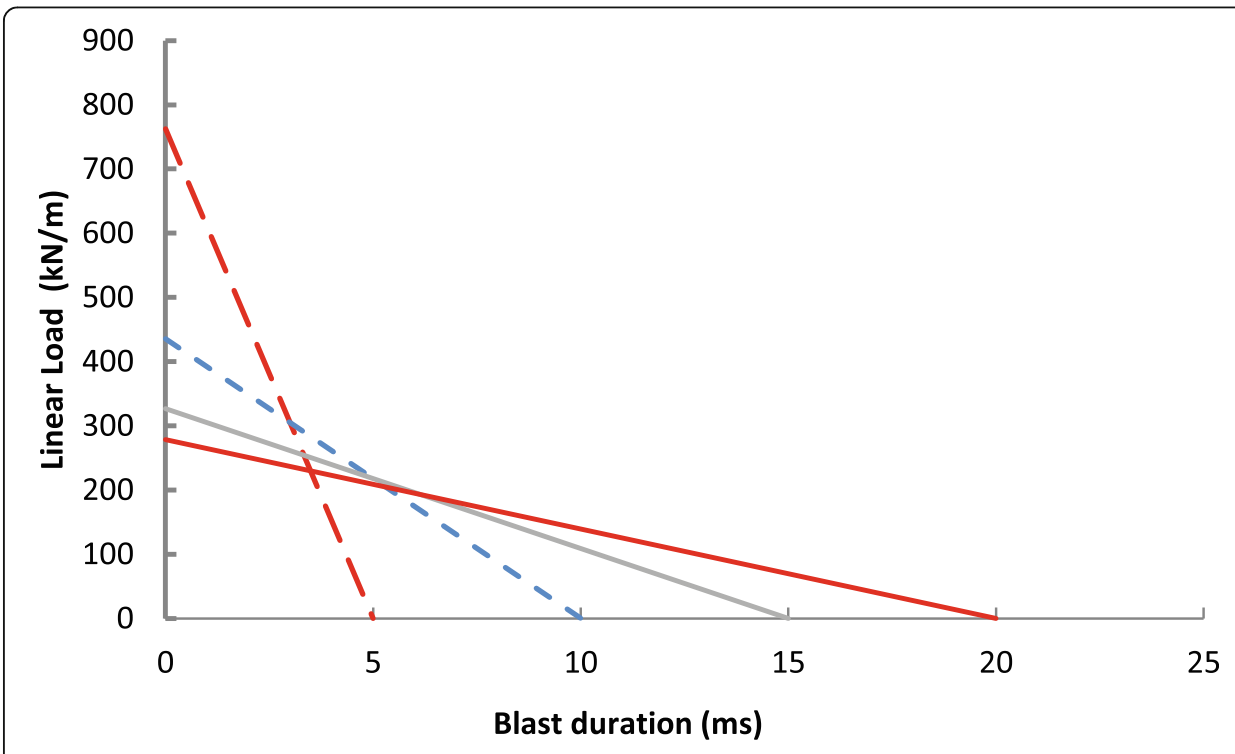

Fig. 22 Blast pressure versus blast duration for connection SC2 


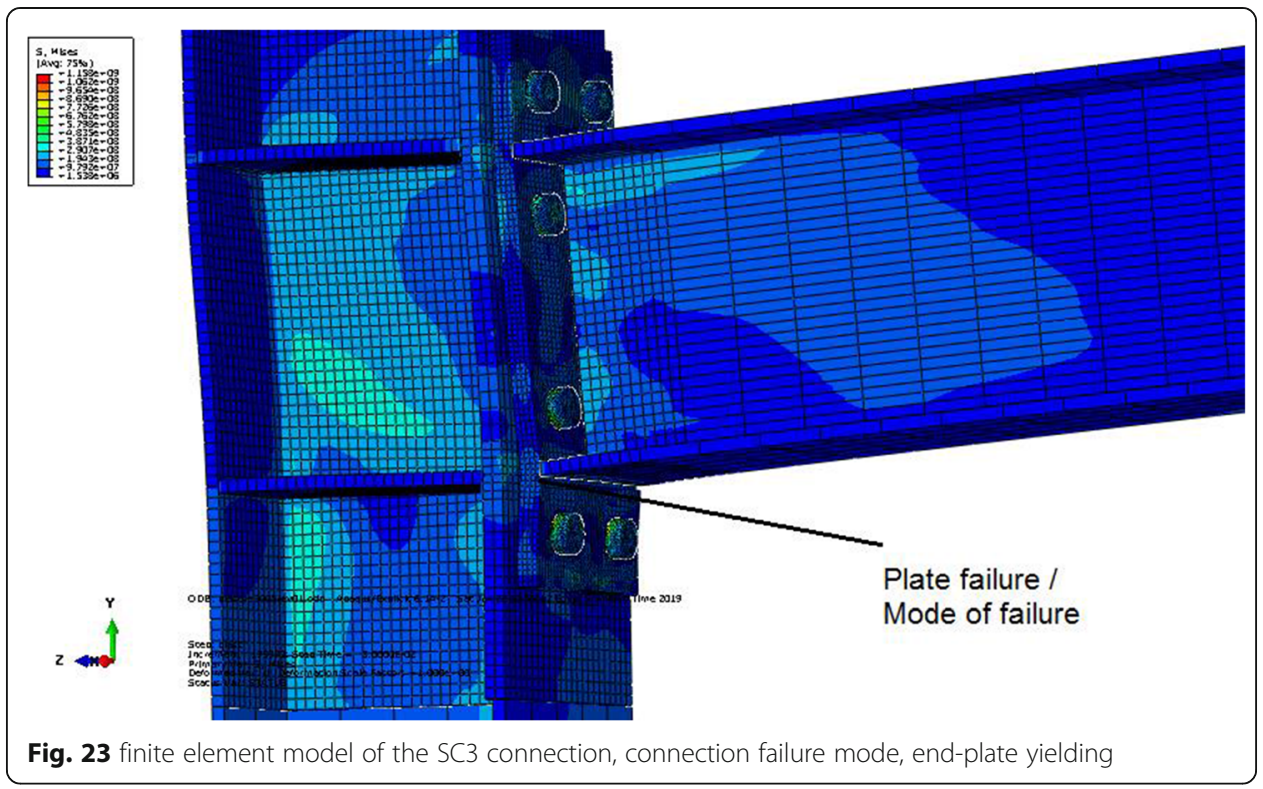

DIF: dynamic increase factor

Applying this concept to the connections SC2 and SC3, it is noted that using DIF = 1.05 provides a lower bound and underestimates the moment capacity of the connection under blast-like loading by 16 to $33 \%$, whereas using a DIF of 1.41 provides an upper bound for the connection capacity (Table 4).

For connection SC3, the rotation capacity of the same connection under dynamic loading was higher by $14 \%$ than the rotation capacity under static loading. Meanwhile, the rotation capacity for the connections SC2 and DR1 under dynamic load

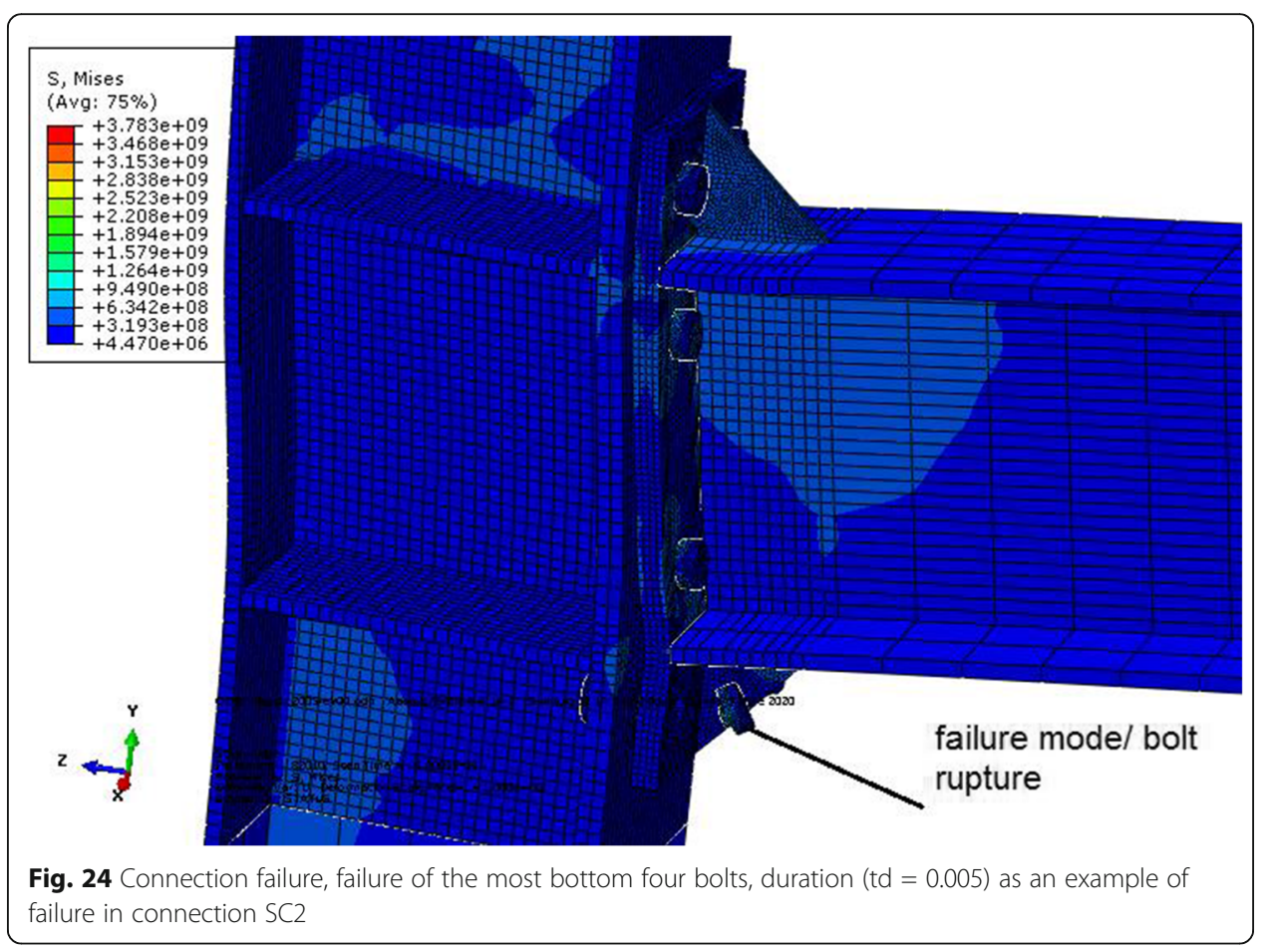




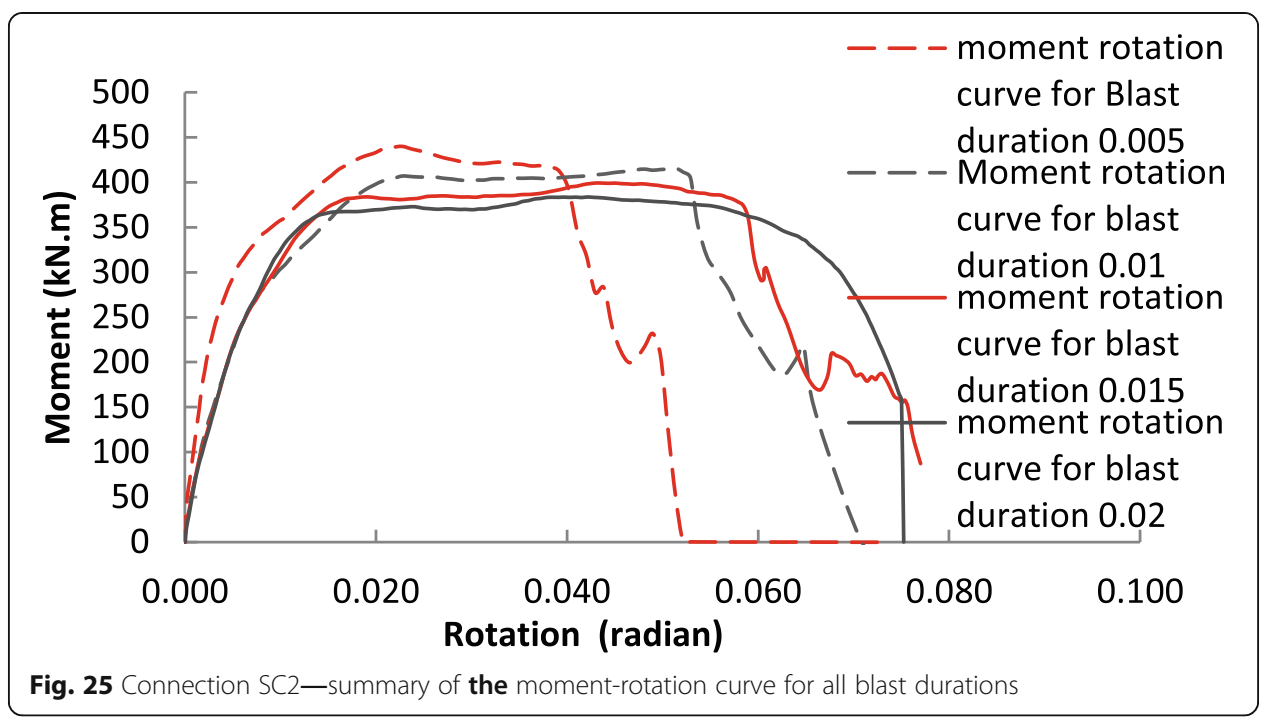

was higher than the static loading by $22 \%$ and $23 \%$, respectively. Hence, under dynamic loading, the connection shows more ductile behavior as compared to static loading conditions.

The plastic energy dissipation $\left(E_{p}\right)$ curves are calculated by ABAQUS software (software output) but using the following equation:

$$
E p=\int_{0}^{t}\left[\int_{V} \sigma^{C} \varepsilon^{\mathrm{pl}} \mathrm{dv}\right] \mathrm{dt}
$$

where:

$E_{p}$ : Plastic energy dissipation

${ }^{c}$ : Undamaged stress

$\varepsilon^{\mathrm{pl}}$ : Plastic strain rate

$v$ : Volume

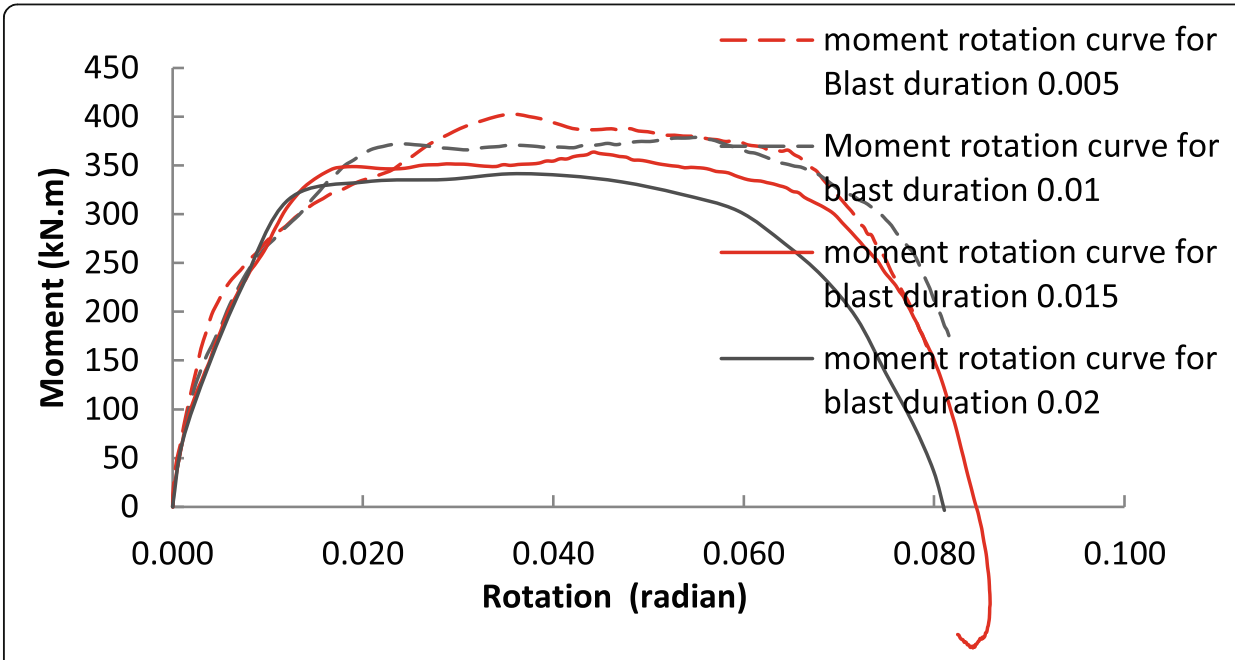

Fig. 26 Connection SC3-summary of the moment-rotation curve for all blast durations 


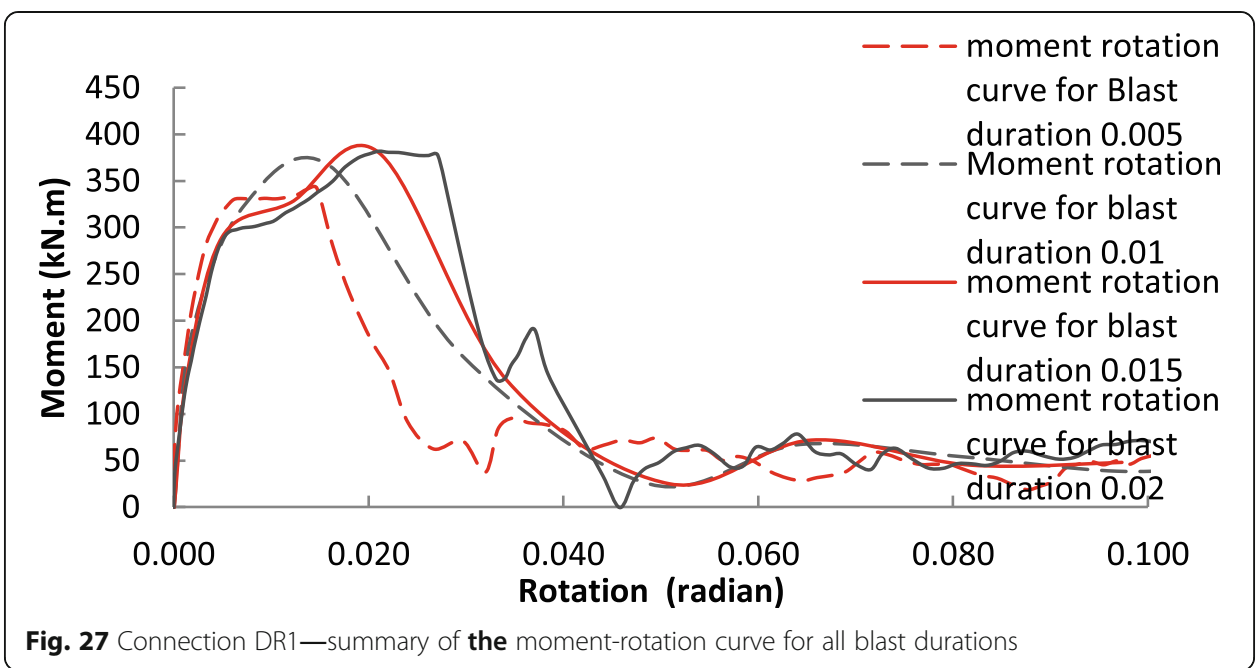

Figure 29 shows that the stiffened connection had higher plastic energy dissipation compared to the unstiffened connection under blast loading by $45 \%$. However, under static loading, the plastic energy dissipation for stiffened connection was higher than the unstiffened connection by a range of $30 \%$ to $37 \%$ (Fig. 30). The plastic energy dissipation for the stiffened connection under blast load is 6.54 times the plastic energy dissipation under static load (Figs. 29 and 30).

For the unstiffened connection under blast load, the plastic energy dissipation under blast loading is 5.95 times the plastic energy dissipation under static load. The dynamic increase factor for stiffened connection (i.e., governed by bolt rupture) was found to range from 1.05 to 1.37. Meanwhile, for unstiffened connection (i.e., end-plate yielding is governing), it was found to be from 1.19 to 1.41 .

A good estimate is proposed by UFC 340-02 that considers DIF from 1.2 to 1.3 for yielding of steel plates. However, 1.3 may be non-conservative in some cases. Also, considering the DIF for ultimate failure of bolts equal 1.05 is generally acceptable as shown on Table 4.

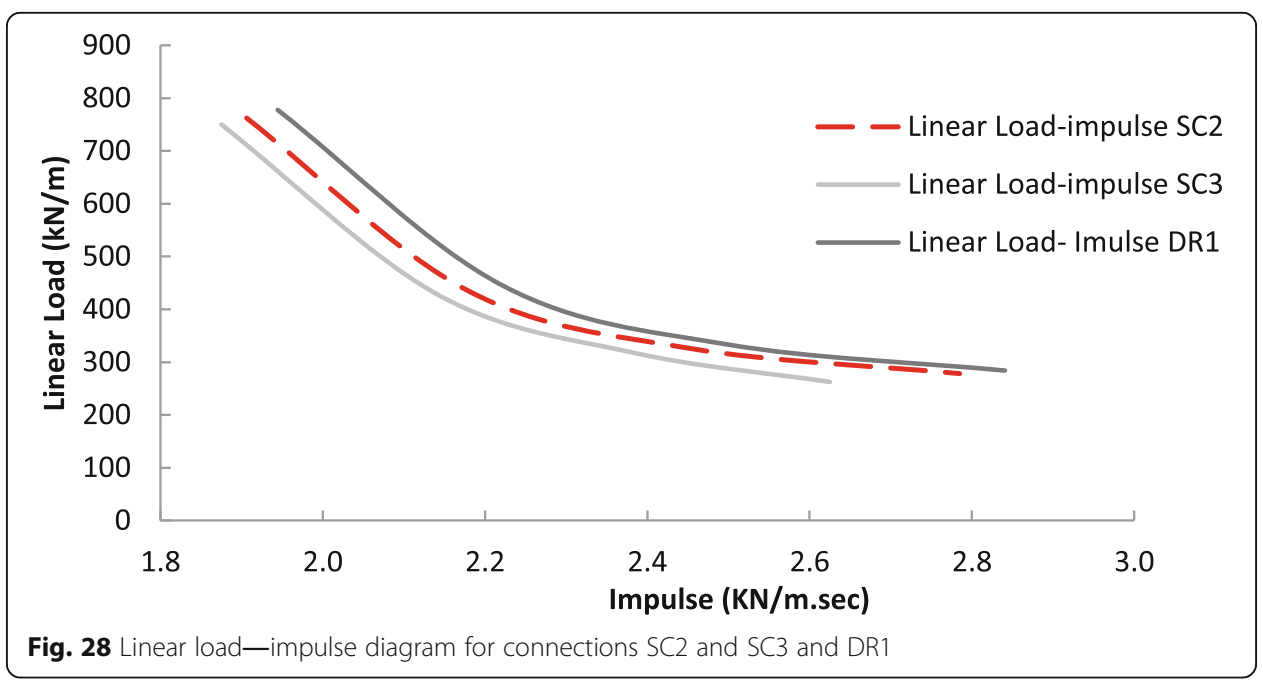


Table 4 Comparing ultimate moments obtained by numerical models vs. values calculated by UFC 340-02, design guides No. 16 and 26, in addition to DIF

\begin{tabular}{|c|c|c|c|c|c|}
\hline Connection & $\begin{array}{l}\text { Static } \\
\text { moment } \\
\text { Numerical } \\
\text { values }\end{array}$ & $\begin{array}{l}\text { Numerical analysis extracted } \\
\text { ultimate moment }\end{array}$ & $\begin{array}{l}\text { DIF } \\
\text { Authors' } \\
\text { computed } \\
\text { values }\end{array}$ & $\begin{array}{l}\text { DIF } \\
\text { UFC } \\
340-02\end{array}$ & Failure mode \\
\hline $\begin{array}{l}\text { SC2-Blast } \\
\text { duration } 0.005\end{array}$ & 322 & 440.3 & 1.37 & 1.05 & $\begin{array}{l}\text { Bolt failure (Fig. } \\
\text { 24) }\end{array}$ \\
\hline $\begin{array}{l}\text { SC2-Blast } \\
\text { duration } 0.01\end{array}$ & 322 & 415.8 & 1.29 & 1.05 & Bolt failure \\
\hline $\begin{array}{l}\text { SC2-Blast } \\
\text { duration } 0.015\end{array}$ & 322 & 389.8 & 1.21 & 1.05 & Bolt failure \\
\hline $\begin{array}{l}\text { SC2-Blast } \\
\text { duration } 0.02\end{array}$ & 322 & 383.8 & 1.19 & 1.05 & bolt failure \\
\hline $\begin{array}{l}\text { SC3-Blast } \\
\text { duration } 0.005\end{array}$ & 286 & 402.1 & 1.41 & 1.3 & $\begin{array}{l}\text { End-plate } \\
\text { yielding (Fig. 23) }\end{array}$ \\
\hline $\begin{array}{l}\text { SC3-Blast } \\
\text { duration } 0.01\end{array}$ & 286 & 378.7 & 1.32 & 1.3 & $\begin{array}{l}\text { End-plate } \\
\text { yielding }\end{array}$ \\
\hline $\begin{array}{l}\text { SC3-Blast } \\
\text { duration } 0.015\end{array}$ & 286 & 363.7 & 1.27 & 1.3 & $\begin{array}{l}\text { End-plate } \\
\text { yielding }\end{array}$ \\
\hline $\begin{array}{l}\text { SC3-Blast } \\
\text { duration } 0.02\end{array}$ & 286 & 341.5 & 1.19 & 1.3 & $\begin{array}{l}\text { End-plate } \\
\text { yielding }\end{array}$ \\
\hline $\begin{array}{l}\text { DR1—Blast } \\
\text { duration } 0.005\end{array}$ & 325 & 342.1 & 1.05 & 1.05 & Bolt failure \\
\hline $\begin{array}{l}\text { DR1—Blast } \\
\text { duration } 0.01\end{array}$ & 325 & 366 & 1.13 & 1.05 & Bolt failure \\
\hline $\begin{array}{l}\text { DR1—Blast } \\
\text { duration } 0.015\end{array}$ & 325 & 379.7 & 1.17 & 1.05 & Bolt failure \\
\hline $\begin{array}{l}\text { DR1-Blast } \\
\text { duration } 0.02\end{array}$ & 325 & 381.9 & 1.17 & 1.05 & Bolt failure \\
\hline
\end{tabular}

\section{Conclusions}

This paper describes the development of finite element models to simulate the behavior of end-plate connections under both static and blast loading. The numerical results are compared to the experimental results [10, 12]. After verification of the model, blast load is applied with a duration ranging from 0.005 to $0.02 \mathrm{~s}$. The work provides pressure impulse diagrams for end-plate connections which may be used as a guide to improve UFC3-340-02 [14] and provide better insight for the design of end-plate connections under blast loading. Moment rotation diagrams for different blast durations are also provided.

The research compares the performance of an unstiffened end-plate connection with two types of stiffened connections; one has a rib stiffener welded to the middle of the end-plate and the other has two stiffeners welded at the edges.

Based on the analyses, the following conclusions were reached:

- The rotation capacity of the same connection under dynamic loading was higher than the rotation capacity under static loading by $14 \%$

- It was observed that the stiffened connection, SC2 had higher plastic dissipation energy compared to the unstiffened connection under blast loading by $45 \%$. However, under static loading the plastic energy dissipation for stiffened connection, SC2 was higher than the unstiffened connection, by a range of $30 \%$ to $37 \%$. 


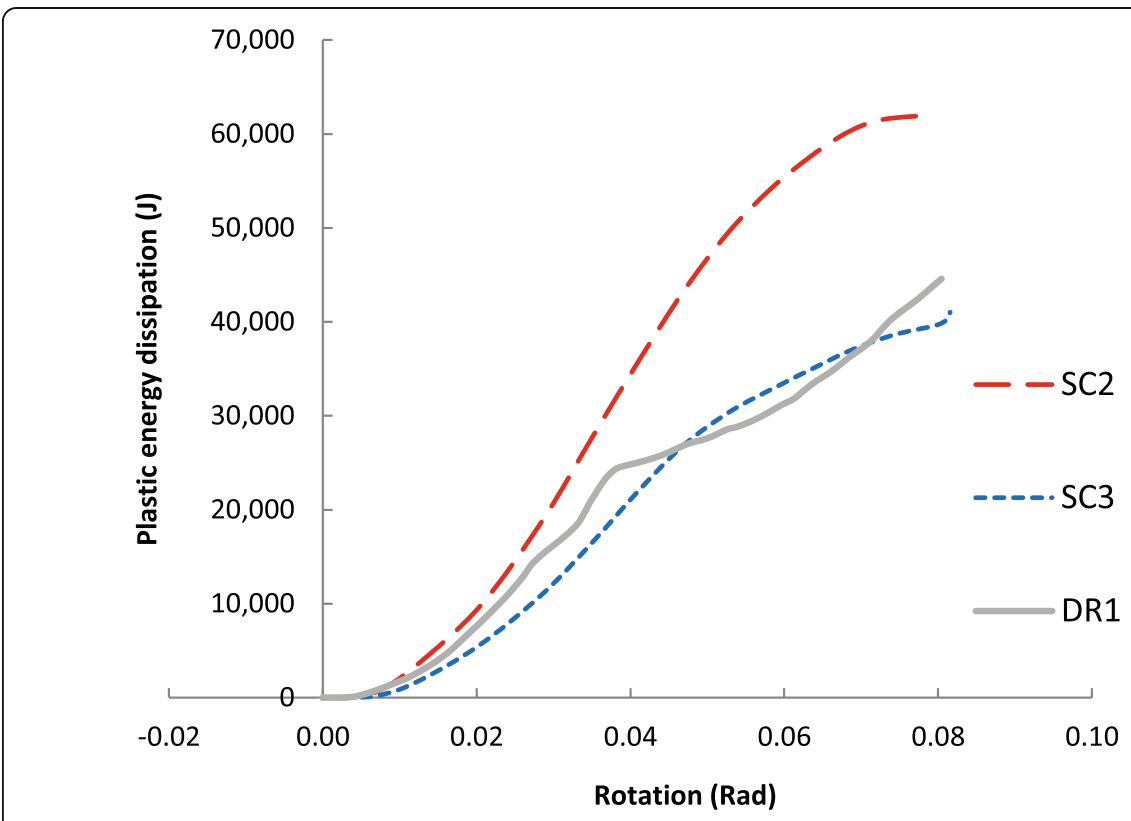

Fig. 29 Plastic energy dissipation for connections SC2, SC3, and DR1 under blast loading and blast duration $0.02 \mathrm{~s}$

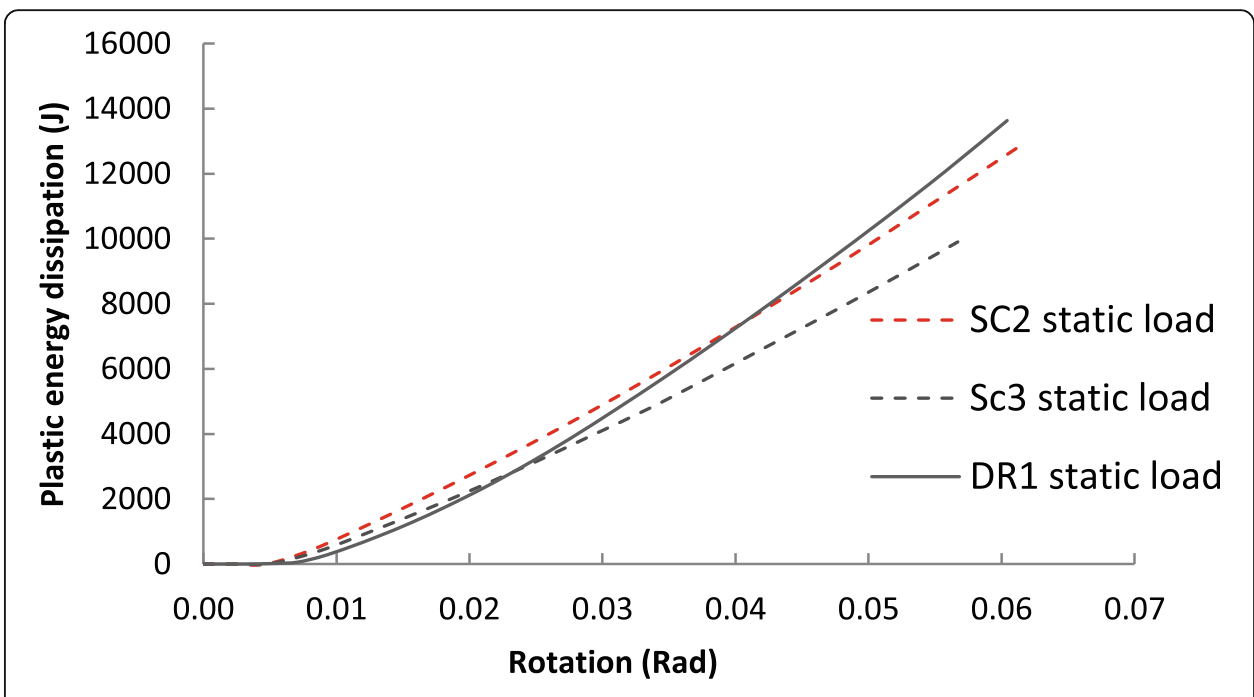

Fig. 30 Plastic energy dissipation for connections SC2, SC3, and DR1 under static loading 
- A conservative estimate for the dynamic increase factor (DIF) was found to be 1.2 for steel yield stress, and 1.05 for bolt failure.

- The dynamic rotation capacities were higher than static ones, and the connections under blast load showed better ductile behavior and higher energy dissipation than under static loading.

- The presence of additional end-plate rib stiffeners improved the maximum pressure that can be sustained by the connection considering the same blast duration.

- The rotation capacity of unstiffened connection was more than the stiffened connection.

\section{Abbreviations}

AISC: American institute of steel construction; DIF: Dynamic increase factor; UFC: Unified facilities criteria

\section{Acknowledgements}

Not applicable

\section{Authors' contributions}

The paper is based on the Ph.D. dissertation of AAO under the supervision of SAM. AAO wrote the initial draft of the manuscript under the supervision of SAM. Both authors developed the ideas and frameworks for the manuscript. All authors read and approved the final version of the manuscript.

\section{Funding}

The authors declare that no fund was received to perform this research.

\section{Availability of data and materials}

The datasets generated and/or analyzed during the current study are available in the [4shared] repository, (https:// www.4shared.com/rar/2Z3Hh8Mzea/new_work.html)

\section{Declarations}

Competing interests

The second Author, SAM, is an associate editor for the Journal of Engineering and Applied Science.

Received: 29 March 2021 Accepted: 26 June 2021

Published online: 08 September 2021

\section{References}

1. Popov EP, Tsai K-C, Engelhart MD (1989) On seismic steel joints and connections. Eng Struct. 11(3):148-162. https://doi. org/10.1016/0141-0296(89)90003-5

2. D'Aniello M, Tartaglia R, Costanzo S, Landolfo R (2017) Seismic design of extended stiffened end-plate joints in the framework of Eurocodes. J Constructional Steel Res 128:512-527

3. Krauthammer T (1999) Blast-resistant structural concrete and steel connections. Int J Impact Eng 22:887-910 https://doi. org/10.1016/S0734-743X (99)00009-3

4. Sabuwala, T.; Linzell, D.; Krauthammer, T.: Finite element analysis of steel beam to column connections subjected to blast loads. Int J Impact Eng 2005; 31:861-876. https://doi.org/https://doi.org/10.1016/j.jijmpeng.2004.04.013, 7.

5. ABAQUS version 2014, Finite element analysis software by simulia, Dassault Systems.

6. TM 5-1300, Structures to resist the effects of accidental explosions, Department of Army, Washington, DC, November 1990.

7. Yim, C.Y.; Krauthammer, T.: Load-impulse characterization for steel connection. Int J Impact Eng, Vol. 36, 2009; 737-745. https://doi.org/https://doi.org/10.1016/j.jijimpeng.2008.09.005, 5

8. Lee, K.; Kim, T.; Kim, J.: Local response of W-shaped steel columns under blast loading. J Struct Eng Mech 2009, Vol. 31, No. 1: 25-38. https://doi.org/https://doi.org/10.12989/sem.2009.31.1.025.

9. Hadianfard, M. A.; Farahani, A.; Jahromi, A. B.: On the effect of steel columns cross sectional properties on the behaviors when subjected to blast loading. J Struct Eng Mech 2012, Vol. 44, No. 4: 449-463. http://dx.doi.org/https://doi.org/10.12 989/sem.2012.44.4.449

10. Grimsmo, E.L.; Clausen, A.H.; Langseth, M.; Aalberg, A.: An experimental study of static and dynamic behaviour of bolted endplate joints of steel. Int J Impact Eng, Vol. 85, 2015, 132-145. https://doi.org/https://doi.org/10.1016/j.ijimpeng.2015.07.001

11. Yang, B.; Wang, H.; Yang, Y.; Kang, S., Zhou, X.; Wang, L.: Numerical study of rigid steel beam-column joints under impact loading. J Constructional Steel Res, Volume 147, August 2018: 62-73. https://doi.org/https://doi.org/10.1016/j.jcsr.2018.04.004

12. Shi, G.; Shi, Y.; Wang, Y.; Bradford, M.A.: Numerical simulation of steel pretensioned bolted end-plate connections of different types and details. J Eng Struct, Volume 30, Issue 10, October 2008: 2677-2686. https://doi.org/https://doi.org/1 0.1016/j.engstruct.2008.02.013.

13. Gilsanz, R.; Hamburger, R.; Barker, D.; Smith J.L.; and Rahimian, A., "Design of blast resistant structures", Steel Design Guide No. 26, American Institute of Steel Construction, Chicago, IL, U.S.A., 2013.

14. Unified Facilities Criteria. Structures to resist the effect of accidental explosions. UFC 3-340-02. 2008

15. Jia, L.; and Kuwamura, H.: Ductile fracture model for structural steel under cyclic large strain loading. J Constructional Steel Res, 2015: 110-121. https://doi.org/https://doi.org/10.1016/j.jcsr.2014.12.002, 106. 
16. Grimsmo, E.L.; Clausen, A.H.; Aalberg, A.; and Langseth, M.: A numerical study of beam-to-column joints subjected to impact. Eng Struct, Vol. 120, 2016, 103-115. https://doi.org/https://doi.org/10.1016/j.engstruct.2016.04.031.

17. Krolo, P.; Grandić, D.; Bulić, M.: The guidelines for modelling the preloading bolts in the structural connection using finite element methods. J Comput Eng 2016, Vol. 2016, Page 8, Article ID 4724312. https://doi.org/https://doi.org/10.11 55/2016/4724312, 1, 8 .

18. Abdel-Aziz, A.: "Performance of end-plate bolted connections under blast loading" Ph.D. Dissertation - under preparation, Structural Eng. Dept., Faculty of Engineering, Cairo University, Egypt.

19. Murray, T.M.; Shoemaker, W.L.: Flush and extended multiple-row moment end-plate connections. Steel Design Guide No. 16, American Institute of Steel Construction, Chicago, IL, U.S.A., 2016

20. Abedini M, Zhang C, Mehrmashhadi J, Akhlaghi E (2020) Comparison of ALE, LBE and pressure time history methods to evaluate extreme loading effects in RC column. Structures. 28:456-466

\section{Publisher's Note}

Springer Nature remains neutral with regard to jurisdictional claims in published maps and institutional affiliations.

Submit your manuscript to a SpringerOpen ${ }^{\odot}$ journal and benefit from:

- Convenient online submission

- Rigorous peer review

- Open access: articles freely available online

- High visibility within the field

- Retaining the copyright to your article 